\title{
A Large-Eddy Simulation Study on the Diurnally Evolving Nonlinear Trapped Lee Waves over a Two-Dimensional Steep Mountain
}

\author{
Haile Xue, ${ }^{\mathrm{a}, \mathrm{b}}$ AND Marco A. Giorgetta ${ }^{\mathrm{b}}$ \\ ${ }^{a}$ State Key Laboratory of Severe Weather, Chinese Academy of Meteorological Sciences, Beijing, China \\ ${ }^{\mathrm{b}}$ Max Planck Institute for Meteorology, Hamburg, Germany
}

(Manuscript received 17 March 2020, in final form 7 October 2020)

\begin{abstract}
The diurnally evolving trapped lee wave over a small-scale two-dimensional steep mountain is investigated in large-eddy simulations based on a fully compressible and nonhydrostatic model [Icosahedral Nonhydrostatic (ICON)] with triangular grids of 50-m-edge length. An idealized atmospheric profile derived from a realistic case is designed to account for influences from the stagnant layer near the surface, the stability of the atmospheric boundary layer (ABL) and the upper-level jet. First, simulations were done to bridge from the linear regime to the nonlinear regime by increasing the mountain height, which showed that larger-amplitude lee waves with longer wavelength can be produced in the nonlinear regime than in the linear regime. Second, the effects of the stagnant layer near the surface and the ABL stability were explored, which showed that the stagnant layer or the stable ABL can play a similar wave-absorbing role in the nonlinear regime as in linear theories or simulations. Third, the role of the upper-level jet was explored, indicating that a stronger (weaker) upper-level jet can help to produce longer (shorter) lee waves. The stable ABL with a stagnant layer can more (less) efficiently absorb the longer (shorter) lee waves due to the stronger (weaker) jet, so that the wave response is more sensitive to the wave-absorption layer when an upper-level jet is present. Finally, the momentum budget was analyzed to explore the interaction between the upper and lower levels of the troposphere, which showed that the momentum flux due to the upward-propagating waves and trapped waves varies with the upper-level jet strength and low-level stagnancy and ABL stability.
\end{abstract}

KEYWORDS: Boundary currents; Downslope winds; Mountain waves; Diurnal effects; Large eddy simulations

\section{Introduction}

This study focuses on the question why trapped lee waves triggered by small-scale steep mountains evolve diurnally with the atmospheric boundary layer (ABL) wind and stability and upper-level jet.

The conventional linear theories can present theoretical solutions by using idealized models of two- or three-layer stability (Scorer 1949; Corby and Wallington 1956; Scorer and Klieforth 1959; Sawyer 1960; Pearce and White 1967; Klemp and Lilly 1975; Zang et al. 2007; Zang and Zhang 2008), but cannot include the complexity arising from nonlinear boundary conditions (e.g., Ólafsson and Bougeault 1997; Jiang et al. 2006), surface heating, multilayer wind/stability profiles (Reinecke and Durran 2008), and nonlinear wave amplification (e.g., Durran 1990). The recently developed wave absorption/reflection theory based on a linear equation set with nonlinear bottom boundary conditions showed that trapped lee waves can be absorbed by the stagnant wind conditions near the surface or a stable boundary layer (Smith et al. 2002; Jiang et al. 2006; Smith et al. 2006; Lott 2007, 2016; Soufflet et al. 2019), but the wave response to a steep mountain is not clear when an upper-level jet is present. The nonlinear theories focus more on the nonlinear wave breaking over significant mountains as the waves are propagating upward, but have no concern about the trapped lee wave evolution over small-scale mountains

Corresponding author: Haile Xue, xuehl@cma.gov.cn
(Clark and Peltier 1977; Clark and Farley 1984; Durran 1986a, 1990). The existing numerical simulations mostly employed constant surface heating or heating-free bottom conditions to investigate different aspects and factors influencing the wave regimes (Doyle and Durran 2002, 2007; Vosper 2004, hereafter V04; Sauer et al. 2016). However, it was found from the Sierra Wave Project (Holmboe and Klieforth 1957) and the French Alps project (Queney et al. 1960; Gerbier and Berenger 1961) that the wave amplitude decreases and wavelength increases in the afternoon which may be caused by diurnal heating. Ralph et al. (1997) suggested that the deepening of the mixed layer thins the elevated stable layer that is a key part of the waveguide and that this thinning causes the systematic temporal increase of the horizontal wavelength.

More recently, both amplitude and wavelength were found to be increased in the afternoon on the southeast edge of the Tibetan Plateau based on a realistic large-eddy simulation (LES) study incorporating multisource observations (Xue et al. 2020, hereafter X20), but the mechanism is still not clear. The absence of lee waves over the Alps has been successfully explained by the linear wave absorption theory (Smith et al. 2002). Jiang and Doyle (2008) simulated the diurnal variation of waves due to an idealized mesoscale but very low mountain (linear regime), which showed the convective boundary layer could significantly weaken mountain waves and reduce the momentum flux. Inspired by the wave absorption theory and simulation, this study explores the roles of the stagnant layer and the ABL stability in the nonlinear regime due to a small-scale $2 \mathrm{D}$ 
steep mountain by using a general circulation model in a LES configuration. Besides, the wave response to the upper-level jet is also investigated. The remainder of the paper is organized as follows. The numerical model is described and a benchmark simulation is carried out in section 2. The design of the numerical experiments and their results are presented in section 3. The momentum budget and our conclusion are given in section 4 and section 5 , respectively.

\section{Model description and benchmarking}

Icosahedral Nonhydrostatic (ICON) is a unified modeling system appropriate for global numerical weather prediction (Zängl et al. 2015) and climate studies (Giorgetta et al. 2018), and regional storm resolving (Klocke et al. 2017) and largeeddy resolving simulations (Dipankar et al. 2015; Heinze et al. 2017). ICON is a fully compressible model that uses an unstructured triangular grid with C-type staggering and a height-based terrain-following coordinate system. It includes the horizontal velocity component normal to the triangle edge $\left(v_{n}\right)$, vertical velocity component $(w)$, density of moist air (denoted as $\rho$ for dry air in this study), virtual potential temperature (denoted as $\theta$ for dry air in this study), and mass fractions of tracers, including the mass fraction of water vapor, and different hydrometers as prognostic variables (none of them used in this study). The arrangement of these variables on the grid is illustrated in the left panel of Fig. 4 of Giorgetta et al. (2018). The velocity component tangential to the triangle edge is diagnosed using the radial basis function reconstruction (Narcowich and Ward 1994). The prognostic equations are integrated in time using the two-time level predictor-corrector scheme except for the terms corresponding to the vertical sound-wave propagation, which are integrated implicitly. The advection scheme for momentum equations in ICON is second-order accurate in both vertical and horizontal directions. Vertical staggering is of Lorenz type (Lorenz 1960), with vertical velocity being defined at interface (half) levels and the remaining prognostic quantities defined at main (full) levels. Full details of the set of equations used in ICON and its numerical treatment can be found in Zängl et al. (2015).

The LES physics package has been implemented in ICON (ICON-LEM) to make it possible to run in LES configuration (Dipankar et al. 2015). The equations are implicitly filtered to separate the resolved and unresolved scale turbulence. The unresolved turbulence is parameterized by a three-dimensional (3D), diagnostic Smagorinsky scheme with modifications from Lilly (1962) to account for thermal stratification (Dipankar et al. 2015; Baldauf and Brdar 2016). The Smagorinsky scheme in ICON is applied to prognostic winds $\left(v_{n}\right)$, potential temperature $(\theta)$, specific humidity and specific cloud liquid water. The idealized simulations by ICON-LEM have been validated against two standard LES models for a dry convective boundary layer and a cloud topped boundary layer for flat surface (Dipankar et al. 2015). Realistic simulations over Germany (Heinze et al. 2017) showed that ICON-LEM can reproduce realistic

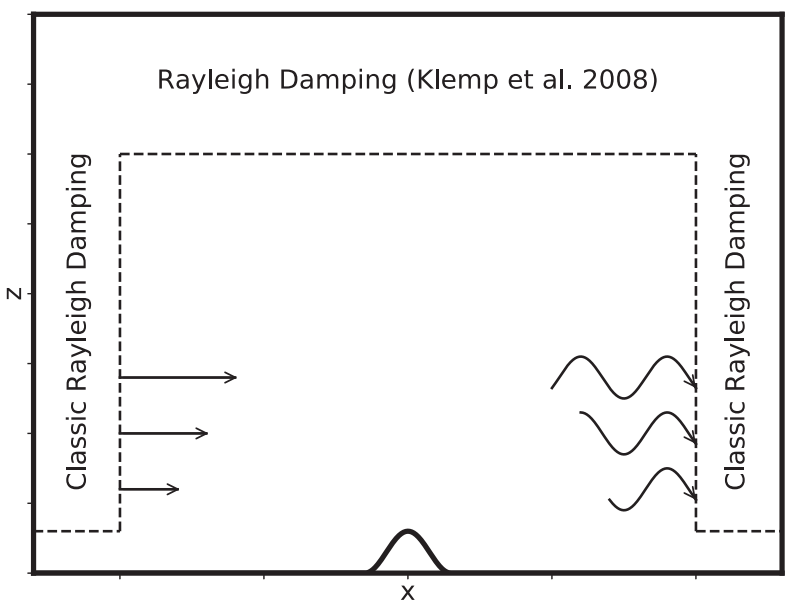

FIG. 1. The vertical cross-sectional sketch for the mountain wave simulation using ICON-LEM. The dashed lines in the sketch indicate the lateral and vertical boundaries of the damping region, where the damping coefficients are at full strength.

turbulent profiles and match the observed variability much better at small-to mesoscales than the coarser resolved model. However, ICON-LEM has not been used to simulate flows over steep mountains. To investigate the response to the different inflow conditions for mountain flows, it is necessary to control the upstream boundary conditions. One direct way is to specify inflow condition and set a radiation outflow condition (Doyle and Durran 2002, 2007). The other way is to choose periodic boundary conditions combined with damping columns near the inflow and outflow boundaries (V04). The third one is the so-called fringe method that force the inflow to the well-developed 3D turbulent flow (e.g., Inoue et al. 2014; Munters et al. 2016). In this study, a very large domain is used to permit the turbulence developing in the upstream region, and we focus more on the downstream wave response to the large-scale background atmospheric condition. To maintain the inflow condition close to the profiles designed later for the experiments, the method of V04 is followed as illustrated in Fig. 1. The periodic boundary conditions are used in both streamwise $(x)$ and spanwise $(y)$ directions. In the vertical direction $(z)$, Rayleigh damping on vertical wind following Klemp et al. (2008) is applied in the top $19-\mathrm{km}$ layer to prevent reflection of gravity waves at the model top. A Rayleigh damping scheme has been implemented in ICON-LEM with two wrapped columns adjacent to the downwind and upwind boundaries. The width and coefficients of the damping columns can be manipulated for different domain sizes or different simulation purposes. Additional transition columns were available in which the damping coefficients are gradually increased from zero to their full values (dashed lines in Fig. 1). The damping columns suppress the spurious sound waves triggered by the initial start in the presence of topography as well as the gravity waves propagating into the periodically connected boundary region. The damping columns start from the surface and the coefficients gradually increase from zero to their full 
TABLE 1. Model configuration.

\begin{tabular}{ll}
\hline \hline \multicolumn{1}{c}{ Parameters } & \multicolumn{1}{c}{ Description } \\
\hline Domain length, width, and height & $204.8 \mathrm{~km} \times 2.6 \mathrm{~km} \times 30.0 \mathrm{~km}$ \\
Cell-edge length & $50 \mathrm{~m}$ \\
Number of layers & 180 \\
Layer depths & From $\Delta z=7 \mathrm{~m}$ at the surface to $\Delta z=533 \mathrm{~m}$ at the model top \\
$\begin{array}{l}\text { Damping width and transition column width } \\
\text { for lateral boundaries }\end{array}$ & 6.4 and $4.0 \mathrm{~km}$ \\
Damping coefficients for lateral boundaries & Below $1500 \mathrm{~m}$ height $1 / 3$ of the full value, then linearly increasing to the full \\
& value at $2000 \mathrm{~m}$; the full values of the damping coefficients are 0.02 for $u$ and \\
& $\theta$ and 0.05 for $w$ \\
Damping coefficient for upper layer & Linearly increasing from 0 at $11 \mathrm{~km}$ to 6.0 at the top of the model at $30 \mathrm{~km}$ in $z$ \\
& direction
\end{tabular}

value above the ABL height. In addition, ICON-LEM uses fourth-order artificial numerical dissipation for numerical stability in the momentum equations and a Smagorinsky type second-order numerical dissipation on temperature fields for stability reasons. Following V04, a 2D cosine mountain profile is included at the middle of the simulation domain as Eq. (1):

$$
h(x)=\left\{\begin{array}{cl}
\frac{h_{m}}{2}\left[1+\cos \left(\frac{\pi x}{\lambda_{h}}\right)\right], & -\lambda_{h} \leq x \leq \lambda_{h}, \\
0, & x \leftarrow \lambda_{h} \vee x>\lambda_{h}
\end{array}\right.
$$

where $\lambda_{h}\left(=5 \mathrm{~km}\right.$ in V04) and $h_{m}$ are mountain half wavelength and full height, respectively.

This particular ICON-LEM configuration for mountain flow simulation is denoted as ICON-MTN. To benchmark ICON-MTN, V04's simulations are reproduced. A constant westerly background wind $\left(U=8 \mathrm{~m}^{-1}\right)$ and a two-layer buoyancy frequency profile are used. In the lowest layer the stratification is neutral and the upper layer is stably stratified with a typical tropospheric value for the buoyancy frequency $\left(N=0.01 \mathrm{~s}^{-1}\right)$. The discontinuity in the background potential temperature $(\Theta)$ between the two layers is represented by imposing a jump $\Delta \Theta$ across a single grid level. Two cases are simulated in which the strength and height of the jump are $3.26 \mathrm{~K}$ at $1600 \mathrm{~m}$ height in case 1 , and $6.53 \mathrm{~K}$ at $800 \mathrm{~m}$ height in case 2 , respectively. The initial profiles are taken from smaller domain $(3.0 \mathrm{~km} \times 2.6 \mathrm{~km})$ simulations using the same resolution, vertical layers, and periodic lateral condition without lateral damping on a flat domain. This is only done for the benchmarking simulation. All other simulations directly use the designed profiles as the initial state and reference state to maintain the inflow condition, instead of using a small domain as in the test following V04. The reason is that those profiles are multiplelayer structured so that the small-domain simulation cannot achieve a steady turbulent state without a proper forcing. As these are 3D large-eddy simulations, the $y$-direction domain should be wide enough to contain large eddies but narrow enough to save the computational resources. As a compromise between these two factors the length in $y$ direction is set to $2.6 \mathrm{~km}$. The Coriolis force is imposed for a latitude of $45^{\circ} \mathrm{N}$ for the benchmarking simulations to be consistent with V04.
However, the Coriolis force is neglected for all other simulations presented here, because the Rossby number is much larger than unity for the mountain. No-slip condition is used at the lower boundary with a roughness length equal to 0.05 and $0.1 \mathrm{~m}$ for benchmarking simulations and all the other simulations, respectively. The simulations can reach a quasi-steady state after 5 -h integration for the waves. Therefore, all the statistics in the subsequent analyses (except for Fig. 3) are based on 1-h model output after 5-h integration with a 5-min output interval. The details of the model configuration are compiled in Table 1.

In the benchmark case 1 , the lee waves can be found above $1500 \mathrm{~m}$ where the potential temperature jump $(\Delta \Theta)$ is located (Fig. 2a). In case $2, \Delta \Theta$ is twice as strong and at half of the height compared to case 1 , so that the waves are stronger (amplitude is larger) and closer to the surface (Fig. 2b). The wave structures are highly similar to Figs. 4 and 5 in V04. The main difference is that more perturbations are present in the ICON-MTN simulations (cf. Fig. 2a to Fig. 4 in V04). As ICON-MTN simulation uses a 3D LES with a 3D Smagorinsky turbulent closure while V04 used a 2D simulation with a mixing-length turbulent closure, the well-resolved turbulence in ICON-MTN can make more perturbations. The lateral damping columns nudge the inflow to the reference flow, but the ABL turbulence is also suppressed to some degree in the inflow region after the damping columns (Figs. 2c,d). However, turbulence can be well developed after a "fetch distance" of a few tens of kilometers in both cases. The mean TKE (turbulent kinetic energy) density shows that a $-5 / 3$ slope can be simulated in the upstream ABL (Figs. 2e,f).

\section{Simulations and results}

\section{a. Experimental design}

A realistic LES combined with observations (X20) showed a diurnally evolving trapped lee-wave phenomenon over a steep small-scale $\left(\lambda_{h} \sim 6-10 \mathrm{~km}\right.$ and $\left.h_{m} \sim 1.8 \mathrm{~km}\right)$ mountain on the southeastern Tibetan Plateau. It showed weak waves in the morning due to the presence of a low-level stagnant stable ABL and amplified and lengthened waves in the afternoon as the ABL developed and the upper-level (between 1.2 and $9.5 \mathrm{~km}$ ) zonal wind strengthened. Figures $3 \mathrm{a}-\mathrm{c}$ show averaged profiles for a $4 \mathrm{~km} \times 4 \mathrm{~km}$ region and a 4 -h period of zonal wind 

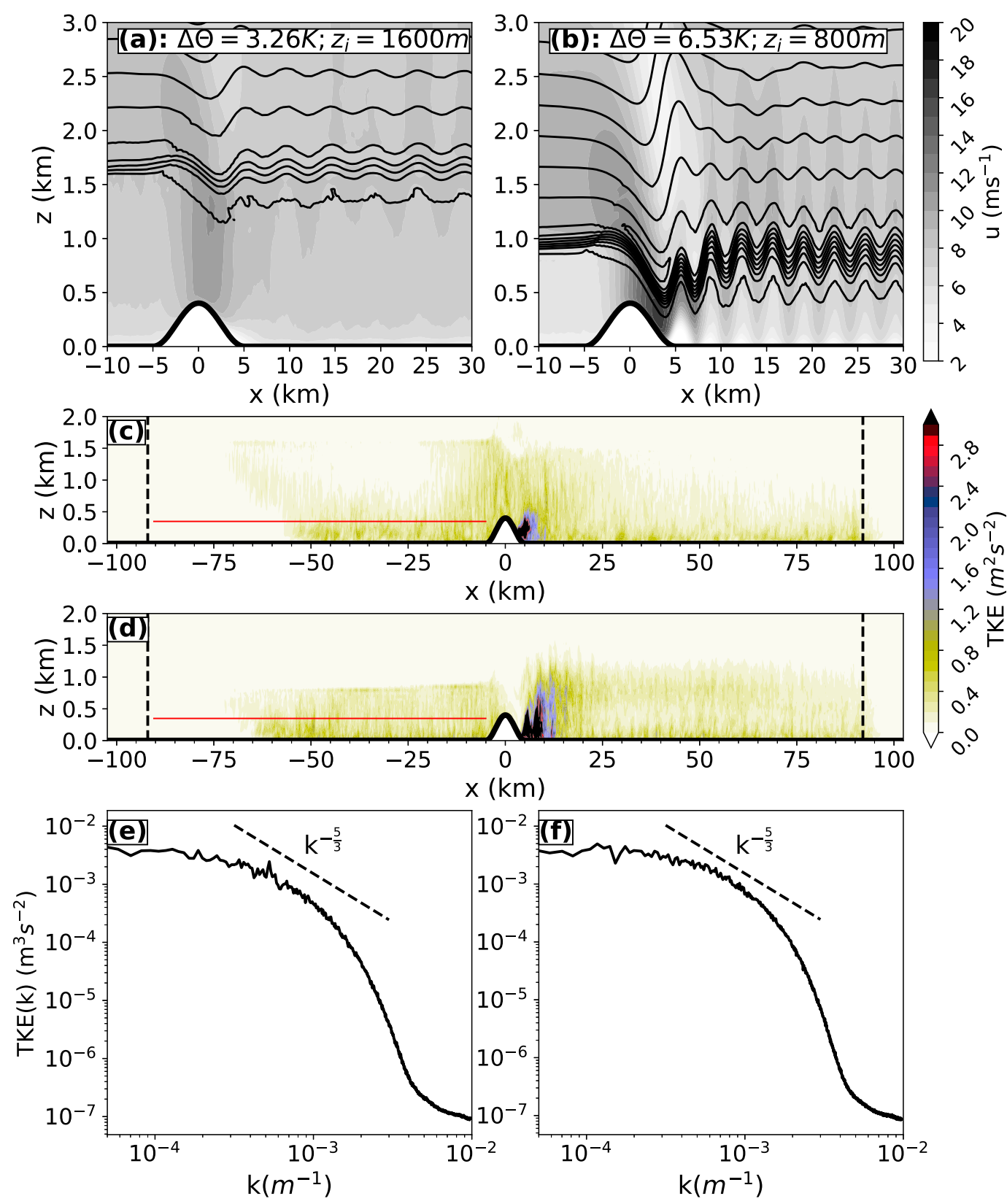

FIG. 2. (a),(b) $u$ (shading) and $\theta$ (contours, interval $=4 \mathrm{~K}$ ), (c),(d) resolved turbulent kinetic energy (TKE), and (e),(f) resolved TKE spectral density. The plots in (a), (c), and (e) are for case 1 and the plots in (b), (d), and (f) are for case 2 of V04. The TKE density profiles in (e) and (f) are calculated from the height (red thin lines) shown in (c) and (d). The vertical dashed lines are the edges of the classic Rayleigh damping columns in Fig. 1.

$(U)$, potential temperature $(\Theta)$, and buoyancy frequency squared $\left(N^{2}\right)$ in the morning and afternoon, which are extracted from the realistic LES of X20 at a place $35 \mathrm{~km}$ upstream of Cang Mountain $\left(25.7^{\circ} \mathrm{N}, 100.2^{\circ} \mathrm{E}\right)$. A strongly sheared and stable troposphere is clearly shown (Figs. 3a,b) in the morning (RMN) and afternoon (RAF). Nevertheless, three apparent differences can be identified between the two periods. The first one is that the stagnant layer near the surface shown in the morning is absent in the afternoon.
The second one is that the stable ABL in the morning is replaced by a near-neutral one so that a quasi-two-layer stability is switched into a quasi-three-layer stability in the troposphere if the stability is assumed as a constant above $2 \mathrm{~km}$ (Fig. 3c). The third one is the increased upper-level westerly wind in the afternoon. To clarify the wave response to the three factors, an idealized profile is designed as shown in Figs. 3d-f. The background zonal wind and stability can be expressed as 

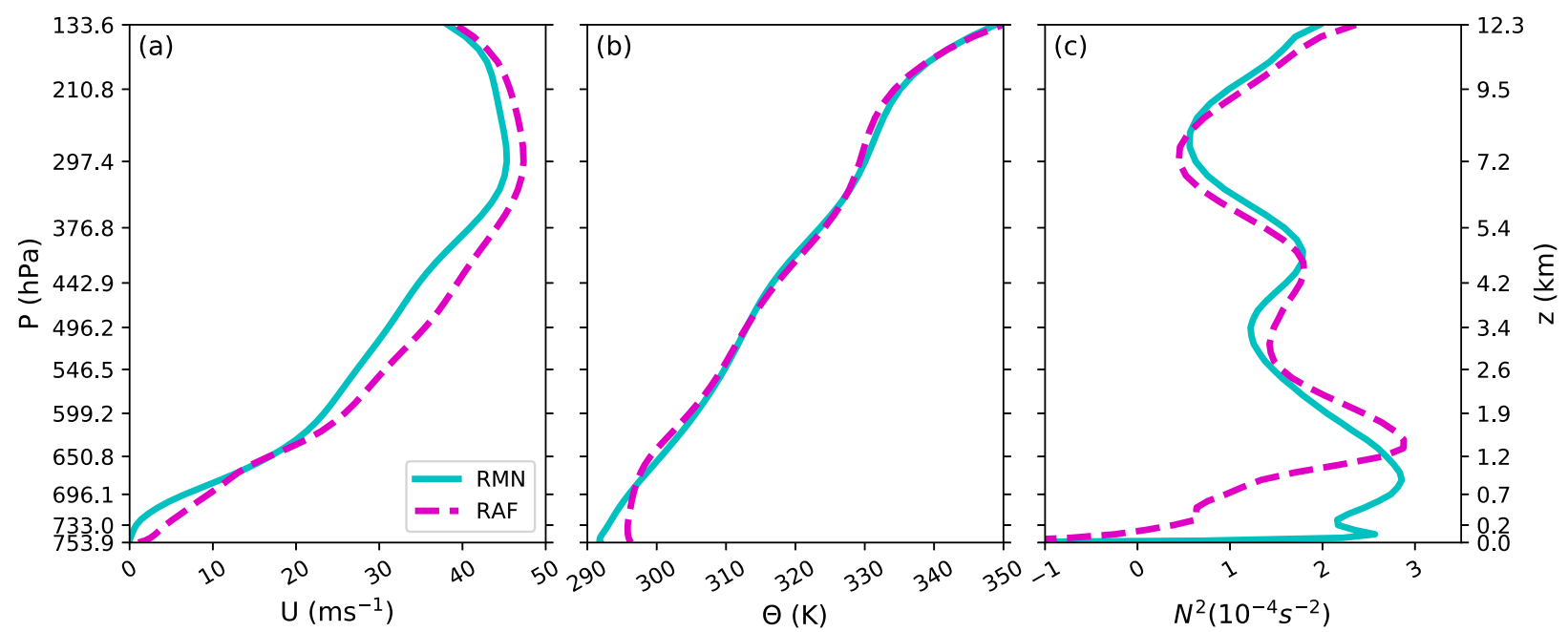

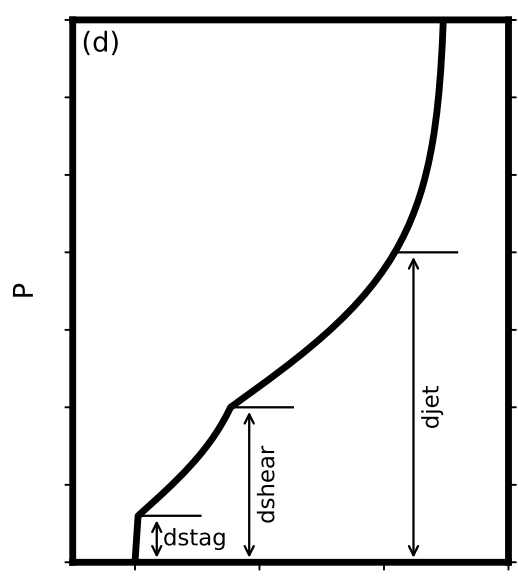

U

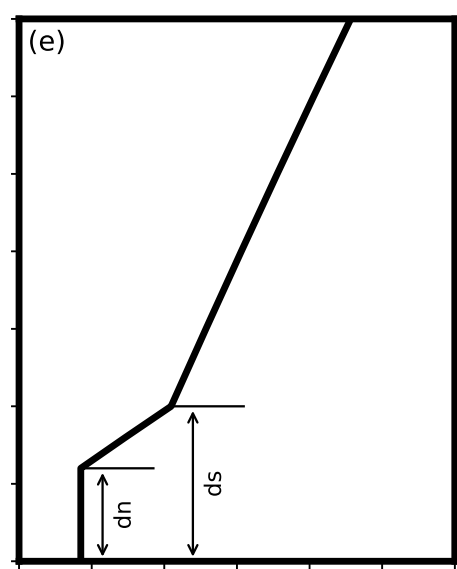

$\Theta$

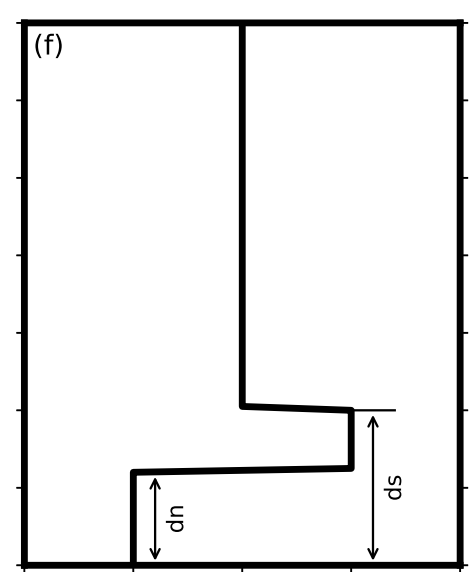

$N^{2}$

Fig. 3. Mean (a) $U$, (b) $\Theta$, and (c) $N^{2}$ for RMN and RAF. (d)-(f) The corresponding profile sketches for $U$, $\Theta$, and $N^{2}$. The heights $d_{\text {stag, }}$, $d_{\text {shear }}, d_{\text {jet }}, d_{n}$, and $d_{s}$ are defined in Eqs. (2) and (3) and provided in Table 2.

$$
U(z)=\left\{\begin{array}{cl}
U_{\text {stag }} \frac{z}{d_{\text {stag }},} & z \leq d_{\text {stag }} \\
U_{\text {stag }}+\left(U_{\text {shear }}-U_{\text {stag }}\right) \tanh \frac{\left(z-d_{\text {stag }}\right)}{\left(d_{\text {shear }}-d_{\text {stag }}\right)}, & \left.\left.d_{\text {stag }}<z \leq d_{\text {shear }} \text { (with jet }\right) \vee d_{\text {stag }} \leq z \text { (without jet }\right), \\
U\left(d_{\text {shear }}\right)+\left[U_{\text {jet }}-U\left(d_{\text {shear }}\right)\right] \tanh \frac{\left(z-d_{\text {shear }}\right)}{\left(d_{\text {jet }}-d_{\text {shear }}\right)}, & \left.z>d_{\text {shear }} \text { (with jet }\right)
\end{array}\right.
$$

wind in cases without a jet, fixed at $20 \mathrm{~m} \mathrm{~s}^{-1}$, as in Lott (2016), and $d_{\text {shear }}$ is the vertical scale of the low-level shear, fixed at $1.5 \mathrm{~km}$ in this study. Different from previous background profiles (e.g., Lott 2016; Soufflet et al. 2019), another shear layer is added here to represent the upper-level jet with maximum background wind for the jet $U_{\text {jet }}$ and the vertical scale of the upper-level jet $d_{\text {jet }}$. Therefore, a wind structure with up to three layers, depending on the depth control parameters $d_{\text {stag }}, d_{\text {shear }}$ and $d_{\text {jet }}$, can be defined, which may include a stagnant layer near the surface, a low-level shear layer and an

where $U_{\text {stag }}$ is the background zonal wind at the top of the stagnant layer with thickness $d_{\text {stag }}$. Where a stagnant layer is used, it is set as $0.5 \mathrm{~m} \mathrm{~s}^{-1}$ rather than null to avoid shear instability (Jiang et al. 2006). $U_{\text {shear }}$ is the maximum background 
TABLE 2. Simulation cases and their parameters in Eqs. (2) and (3). Other parameters in Eqs. (2) and (3): $d_{\text {shear }}=1500 \mathrm{~m}, U_{\text {shear }}=$ $20 \mathrm{~m} \mathrm{~s}^{-1}, N_{0}=0 \mathrm{~s}^{-1}, N_{1}=0.0158 \mathrm{~s}^{-1}$, and $N_{2}=0.0124 \mathrm{~s}^{-1}$.

\begin{tabular}{|c|c|c|c|c|c|c|c|c|}
\hline Case name & Purpose & $h_{m}(\mathrm{~m})$ & $d_{\text {stag }}(\mathrm{m})$ & $U_{\text {stag }}\left(\mathrm{m} \mathrm{s}^{-1}\right)$ & $d_{\text {jet }}(\mathrm{m})$ & $U_{\text {jet }}\left(\mathrm{m} \mathrm{s}^{-1}\right)$ & $d_{n}(\mathrm{~m})$ & $d_{s}(\mathrm{~m})$ \\
\hline $\mathrm{RMN}$ & Response to the realistic profiles & \multirow{2}{*}{\multicolumn{7}{|c|}{$\begin{array}{l}\text { Realistic morning profile; see text } \\
\text { Realistic afternoon profile; see text }\end{array}$}} \\
\hline RAF & & & & & & & & \\
\hline L1N01 & \multirow{4}{*}{$\begin{array}{l}\text { Response to nondimensional mountain } \\
\text { height }\end{array}$} & 200 & 0 & 0 & $\infty$ & 20 & 0 & 0 \\
\hline L1N03 & & 500 & 0 & 0 & $\infty$ & 20 & 0 & 0 \\
\hline L1N06 & & 1000 & 0 & 0 & $\infty$ & 20 & 0 & 0 \\
\hline L1N11 & & 1800 & 0 & 0 & $\infty$ & 20 & 0 & 0 \\
\hline L2 & \multirow{4}{*}{$\begin{array}{l}\text { Response to stagnant layer and ABL } \\
\text { stability }\end{array}$} & 1800 & 0 & 0.5 & $\infty$ & 20 & 0 & 1500 \\
\hline L2Stag & & 1800 & 400 & 0.5 & $\infty$ & 20 & 0 & 1500 \\
\hline L3 & & 1800 & 0 & 0.5 & $\infty$ & 20 & 1000 & 1500 \\
\hline L3Stag & & 1800 & 400 & 0.5 & $\infty$ & 20 & 1000 & 1500 \\
\hline L3J30 & \multirow{8}{*}{$\begin{array}{l}\text { Response to upper-level jet strength with } \\
\text { morning or afternoon ABL condition }\end{array}$} & 1800 & 0 & 0.5 & 7000 & 30 & 1000 & 1500 \\
\hline L2StagJ30 & & 1800 & 400 & 0.5 & 7000 & 30 & 0 & 1500 \\
\hline L3J40 & & 1800 & 0 & 0.5 & 7000 & 40 & 1000 & 1500 \\
\hline L2StagJ40 & & 1800 & 400 & 0.5 & 7000 & 40 & 0 & 1500 \\
\hline L3J50 & & 1800 & 0 & 0.5 & 7000 & 50 & 1000 & 1500 \\
\hline L2StagJ50 & & 1800 & 400 & 0.5 & 7000 & 50 & 0 & 1500 \\
\hline L3J60 & & 1800 & 0 & 0.5 & 7000 & 60 & 1000 & 1500 \\
\hline L2StagJ60 & & 1800 & 400 & 0.5 & 7000 & 60 & 0 & 1500 \\
\hline
\end{tabular}

upper-level jet layer. The depth parameters defining the wind profiles used in this study are compiled in Table 2. As for the stability in Eq. (3), a three-layer structure is designed as well, with buoyancy frequencies $N_{0}=0 \mathrm{~s}^{-1}$ for the neutral layer in the ABL with depth $d_{n}, N_{1}=0.0158 \mathrm{~s}^{-1}$ for the strong stable layer between $d_{n}$ and $d_{s}$, and $N_{2}=0.0124 \mathrm{~s}^{-1}$ for the less stable layer above the strong stable layer. The three stability values are fixed in this study, but the number of the layers can be modified by setting the layer depth values.

To bridge from the linear theory to the nonlinear regime that is concerned in this study, a constant stability and low-level shear wind profile with null wind at the surface is used for the first series of simulations. Therefore, both the surface stagnant layer and the upper-level jet are excluded, and the neutral $\mathrm{ABL}$ and inversion layer (strong stable layer above the ABL) are also ignored. The specific parameters for these experiments, named L1N01, L1N03, L1N06, and L1N11, can be found in Table 2. They differ only in the nondimensional mountain height $\left(H_{N}=N_{2} h_{m} / U_{\text {shear }}\right)$ with values of $0.1,0.3$, 0.6 , and 1.1 , respectively. The $2 \mathrm{D}$ cosine mountain (V04) is replaced by a witch of Agnesi profile:

$$
h(x)=\frac{h_{m} a^{2}}{a^{2}+x^{2}},
$$

with a fixed half-width $a$ of $3 \mathrm{~km}$ and varied mountain height $h_{m}$ (refer to Table 2). Please note that $a$ in Eq. (4) is measured at the height $h_{m} / 2$ (e.g., Doyle and Durran 2002), while the half wavelength $\lambda_{h}$ in Eq. (1) is measured at the base of the mountain.

To explore the lee-wave responses to the surface stagnant layer and stability without upper-level jet, a second series of simulations named L2, L2Stag, L3, and L3Stag (Table 2) are carried out. "L2" and "L3" in the names refers to the stability profile having two and three layers, respectively, while "Stag" indicates that a stagnant layer has been added at the surface. The specific parameters can be found in Table 2 as well.

Finally, the last series of simulations are carried out to explore the wave response to the morning $\mathrm{ABL}$ or afternoon ABL with a series of jet strengths (from J30 to J60 as in Table 2). However, the stagnant layer and ABL stability will not be investigated separately with various jets. The stagnant layer and strong stable ABL are combined to represent a morning $\mathrm{ABL}$ condition, while the neutral $\mathrm{ABL}$ without stagnant layer represents an afternoon ABL condition.

\section{b. Validating idealized cases for morning and afternoon conditions}

To validate the above idealization of the profiles extracted from X20, two additional simulations RMN and RAF are carried out by using the realistic morning and afternoon profiles for the background wind and stability to compare with L2StagJ40 and L3J50, respectively. Besides the ABL condition difference between morning and afternoon, the jet strengths are also different from the morning to afternoon. The jet maximum wind at $7.2 \mathrm{~km}$ is about $45 \mathrm{~m} \mathrm{~s}^{-1}$ in the morning and $48 \mathrm{~m} \mathrm{~s}^{-1}$ in the afternoon (Fig. 3a). However, the simplified wind profiles are not exactly the same as the realistic ones. Therefore, L2StagJ40 can partly represent a relatively weaker jet with a stagnant layer and stable ABL, while L3J50 refers to a stronger jet with a neutral ABL without a stagnant layer. Note that the zonal wind has been set as constant above $7.5 \mathrm{~km}$ for the realistic-profile simulations to avoid the complexity that would arise from the wind shear in the stratosphere. Figures $4 \mathrm{a}$ and $4 \mathrm{c}$ show the section of normalized vertical wind (normalized by the maximum amplitude $W_{N}$ of each case) for the RMN and RAF simulations. In the morning, relatively weak lee waves are present near the mountain with three identified crests (Fig. 4a), while stronger and longer lee waves fill the whole space down to the outflow damping boundary in the 

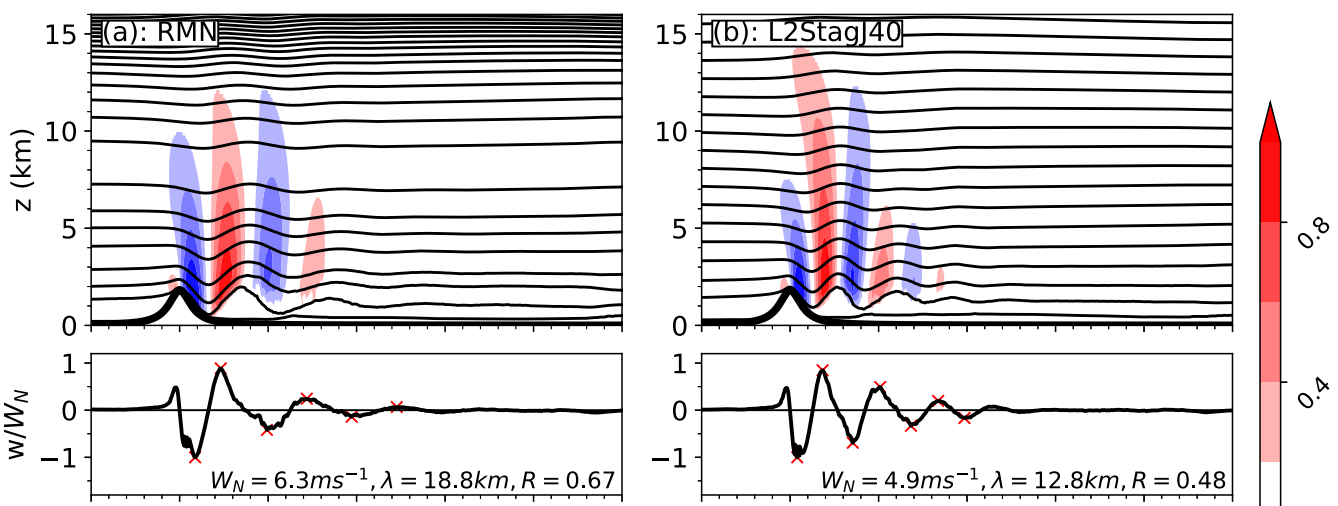

$0^{\infty}$
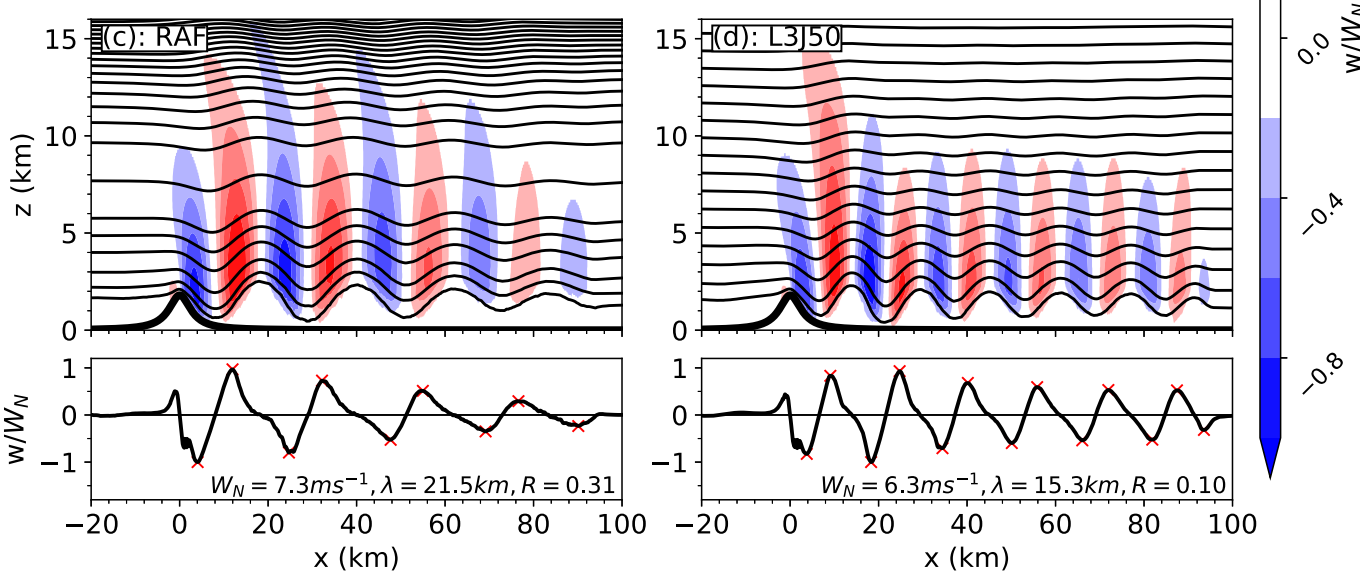

FIG. 4. The vertical cross sections of mean normalized vertical wind (shaded) and $\theta$ (contours) for (a) RMN, (b) L2StagJ40, (c) RAF, and (d) L3J50. The mean normalized vertical wind at heights between 1.2 and $2.0 \mathrm{~km}$ is shown under each vertical cross section. The $W_{N}$ value indicated in each subplot is the maximum amplitude that is used for the normalization. The red crosses indicate the identified crests and troughs.

afternoon (Fig. 4b). Note that crests and troughs in this study refer to the perturbation $\mathrm{w}$ rather than the streamline displacement. The maximum amplitude $W_{N}$ and mean wavelength $\lambda$ are increased by around $1 \mathrm{~m} \mathrm{~s}^{-1}$ and $2.7 \mathrm{~km}$, and the mean wave-damping ratio $R$ is reduced by 0.36 . Note that $R$ is unity minus the mean ratio of the amplitude between a crest (trough) and the nearest upstream crest (trough) and the average is taken from the first crest (trough) to the crest (trough) that has been reduced by $90 \%$ with respect to the first one or to the last crest (trough) if the waves are still strong at the outflow boundary. The value of $\lambda$ is averaged in the same distance as $R$. The simulations of L2StagJ40 and L3J50 show a high similarity in the wave response to the morning ABL with weaker jet of RMN and the afternoon ABL with stronger jet of RAF. The magnitude of the changes in $W_{N}, \lambda$, and $R$ is quite similar to those using the realistic profiles. However, the three parameters are relatively smaller than those of the realistic-profile simulations. Although we have extracted the main characteristics of the realistic profiles to build the idealized profiles, there are still some differences. The first one is that above the jet, where the stratification is getting stronger in the realistic situation, but is constant for the idealized profiles. The other one is that the shear in and above the ABL is different between the realistic and the idealized situations. The stratification and wind shear can both influence the Scorer parameter and therefore the wavelength, and the low-level shear can also influence the Richardson number and therefore the wave absorption and wave amplitude. Despite these differences, the wave response to the idealized profile is also qualitatively similar to the realistic simulation shown in X20. As the domain in X20 is small, only the first wavelength for the potential temperature is included in the domain, with a wavelength of about $19 \mathrm{~km}$ in the afternoon that is comparable to the wavelength in L3J50. While the wavelength in the morning in X20 is only about $9 \mathrm{~km}$, which may be because of the deep stagnant layer located both in the upstream valley and downstream basin. It has been shown that the deep stagnant layer can reduce the effective mountain size so that both wavelength and wave amplitude are changed (Smith et al. 2002). Overall, the idealized profile is considered to be able to represent the main characteristic of the realistic profile for our research objective in this study.

\section{c. Wave response to the nondimensional mountain height}

As the objective of this study is to explore lee waves induced by a flow over a steep mountain, nonlinear effects must be involved. The normalized vertical wind for the cases L1N01, L1N03, L1N06, and L1N11 is displayed in Fig. 5. It is clear that 

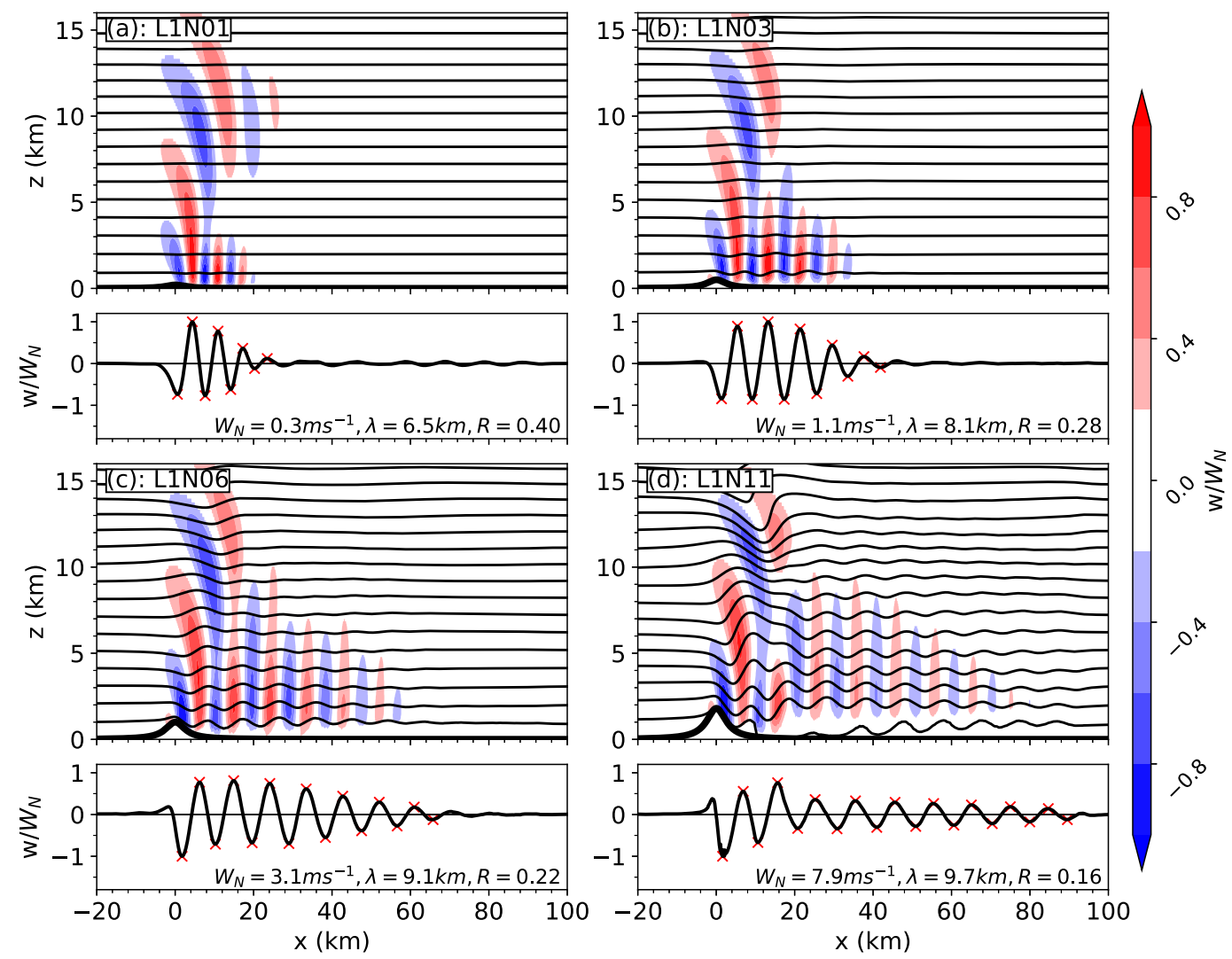

FIG. 5. As in Fig. 4, but for the simulations on the response to nondimensional mountain: (a) L1N01, (b) L1N03, (c) L1N06, and (d) L1N11.

the waves for the four cases are partly trapped and partly upward propagating as predicted in linear theory when the Richardson number $\left[\mathrm{Ri}=\left[\left(N_{2} d_{\text {shear }}\right)^{2} / U_{\text {shear }}^{2}\right]\right]$ can be calculated as 0.84 . The mean wavelength $\lambda$ for L1N01 is $6.6 \mathrm{~km}$ (Fig. 5a) close to the solution of linear theory of around $6 \mathrm{~km}$ (private communication with Lott). The maximum amplitude $W_{N}$ is dramatically increased as $H_{N}$ increases from 0.1 to 1.1 (Fig. 5). The contours of the potential temperature at heights between 12 and $15 \mathrm{~km}$ in the lee of the mountain are nearly vertical for the case of L1N11, which indicates that the waves are nearly breaking even though Rayleigh damping (Klemp et al. 2008) is applied above $11 \mathrm{~km}$. The mean wavelength $\lambda$ increases with $H_{N}$ from $6.5 \mathrm{~km}$ for L1N01 to $9.7 \mathrm{~km}$ for L1N11. The wavelength increasing with the nonlinearity is not consistent with the previous studies (e.g., V04; Teixeira et al. 2013; Sachsperger et al. 2015). However, these studies focused more on the strength and height of the inversion rather than on the mountain height as a cause of nonlinearity. In linear theory, the wavelength is an implicit function of the Froude number and independent of the mountain shape (height and width) (e.g., Scorer 1949; V04). However, the vertical atmospheric structure determines the wavelength that can exist at each layer due to the Scorer parameter, but the shape of the terrain determines the strength of the forcing applied to each wavelength (Durran 1986b). In the series of our simulations with different mountain heights, the buoyancy frequency $N$ is constant and the background wind $U$ increases in the lower layer (below $1.5 \mathrm{~km}$ ) so that the Scorer parameter decreases with height. At a fixed height, the intercept width of the mountain is increasing with the mountain height $h_{m}$. Therefore, the higher mountain will produce forcings on a wider wavenumber range of which the longer waves dominate the trapped lee waves, and the wavelength increases with mountain height. As for the wave amplitude, it is well confirmed by the existing studies (e.g., V04; Sachsperger et al. 2017) that the severer nonlinear effect can result in larger amplitude. The nonlinear acceleration of the flow in the lee wave region may dramatically change the environmental background. Therefore, the local stability may be modified and consequently influence the wave reflection at the surface (Lott 2007; Soufflet et al. 2019). A parameter related to the lee-wave propagation is the filtered Richardson number, $\mathrm{Ri}_{f}=N_{f}^{2} /\left(\partial u_{f} / \partial z\right)^{2}$ [named "large-scale" Richardson number in Soufflet et al. (2019)], which is calculated locally from the filtered buoyancy frequency $N_{f}$ and filtered wind $u_{f}$ shear (here we used a running mean with a window length of $10 \mathrm{~km}$ as the filter). $\mathrm{Ri}_{\mathrm{f}}$ represents an averaged instability induced by the local flow rather than the background flow instability. Scinocca and Peltier (1989) and Peltier and Scinocca (1990) showed that the Kelvin-Helmholtz (K-H) instability can be produced by the downslope windstorm. As the downslope wind can produce large shear near the 

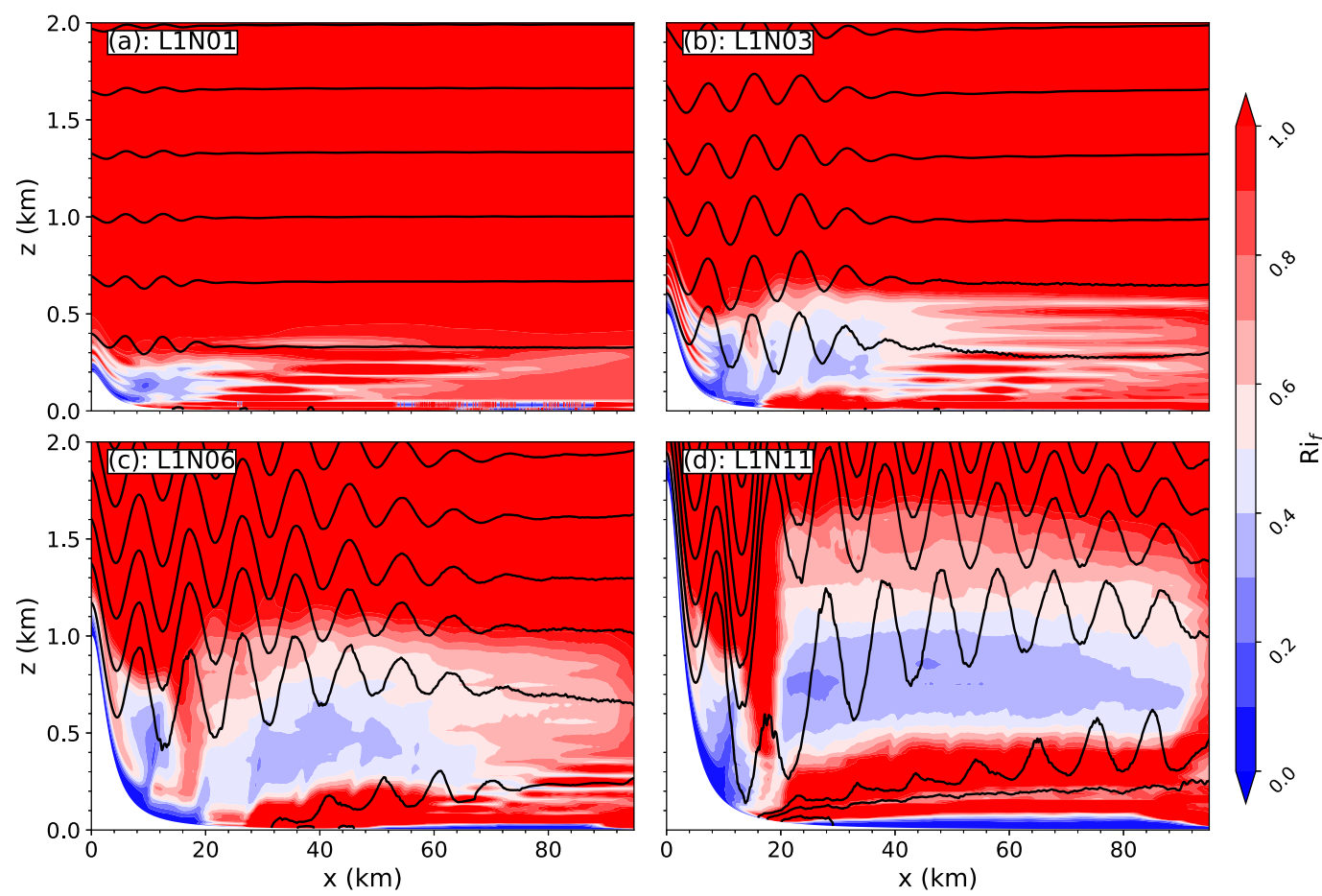

FIG. 6. Vertical cross sections of $\mathrm{Ri}_{f}$ (shaded) and $\theta$ (black contours) for (a) L1N01, (b) L1N03, (c) L1N06, and (d) L1N11.

surface, the K-H instability should refer to a low $\mathrm{Ri}_{f}$. When $H_{N}$ is around unity, the downslope wind can extend much farther than when $H_{N}$ is small. Therefore, the K-H instability layer (or low- $\mathrm{Ri}_{f}$ layer) induced by the downslope wind can also extend much farther with $H_{N}$ closer to unity. Figure 6 shows that the lee-wave extension is closely related to the smaller $\mathrm{Ri}_{f}$ in the lowest $1 \mathrm{~km}$. It means that the impact of the nonlinearity reduces the downstream flow stability, which in turn plays a role as wave reflection layer in facilitating the wave extension to the downstream. Therefore, Fig. 5 displays that the waves are extended further downstream and the mean wave-damping ratio $R$ is slightly reduced as $H_{N}$ increased.

\section{d. Wave response to the stagnant layer and ABL stability}

Figure 7 shows the normalized vertical wind for the cases L2, L2Stag, L3, and L3Stag. Still, all cases display that the waves are partly trapped and partly upward propagating. First, the comparison can be done between L1N11 (Fig. 5d) and L2 (Fig. 7a) which indicates that the maximum amplitude $W_{N}$ is reduced and the mean wave-damping ratio $R$ is increased only by increasing the stability of the ABL. Inversely, by reducing the ABL stability but maintaining the very stable layer just above the ABL (the inversion), as in L3, amplifies $W_{N}$ and reduces $R$ (Figs. 7a,c). This is also true when the surface stagnant layer is present, as in L2Stag and L3Stag (Figs. 7b,d). Note that absorption may already occur to the first trough at the beginning that is not included in the calculation of $R$. Therefore, $R$ may underestimate the actual wave absorption when $W_{N}$ is relatively small, but the wave absorption affecting the first trough can be indicated by $W_{N}$ to some degree. The mean wavelength $\lambda$ seems to be not very sensitive to the lowlevel stability. Note that the stagnant layer is much thinner than the mountain height here. Therefore, the ABL stability still plays a similar role as in linear theory and simulation (e.g., Jiang et al. 2006; Lott 2007) to reduce the lee wave amplitude and propagation. Similar to the increased ABL stability, $W_{N}$ is reduced and $R$ is increased in the presence of the stagnant layer (Fig. 7). Further it is found again that $\lambda$ is not sensitive to the presence of the stagnant layer. The wave absorption from the ABL stability and stagnant layer can be superimposed so that $W_{N}$ is smallest in L2Stag and biggest in L3 (Figs. 7b,c), respectively, while $R$ behaves inversely for the two cases. Therefore, the low-level stagnant layer and ABL stability can work together or solely to contribute to the wave absorption also in the nonlinear regime of the presented simulations, as in linear theories and simulations (e.g., Lott 2007; Jiang et al. 2006).

\section{e. Wave response to the upper-level jet}

Figure 8 shows the normalized vertical wind for the cases L3J40, L2StagJ40, L3J50, and L2StagJ50. Compared to the cases L3 and L2Stag, the lee waves of these four cases are more trapped as the wave shape seen in the potential temperature contours are rapidly flattening with increasing height, which can be easily interpreted as the result of the Scorer parameter reduction due to the upper-level jet of strength $U_{\text {jet }}$. The stable atmospheric flow over a mountain can produce different wavenumber waves. Of these waves, how much could be upward propagating or trapped is determined by the upper-level Scorer parameter (i.e., $U_{\text {jet }}$ if $N$ keeps constant). As $U_{\text {jet }}$ 

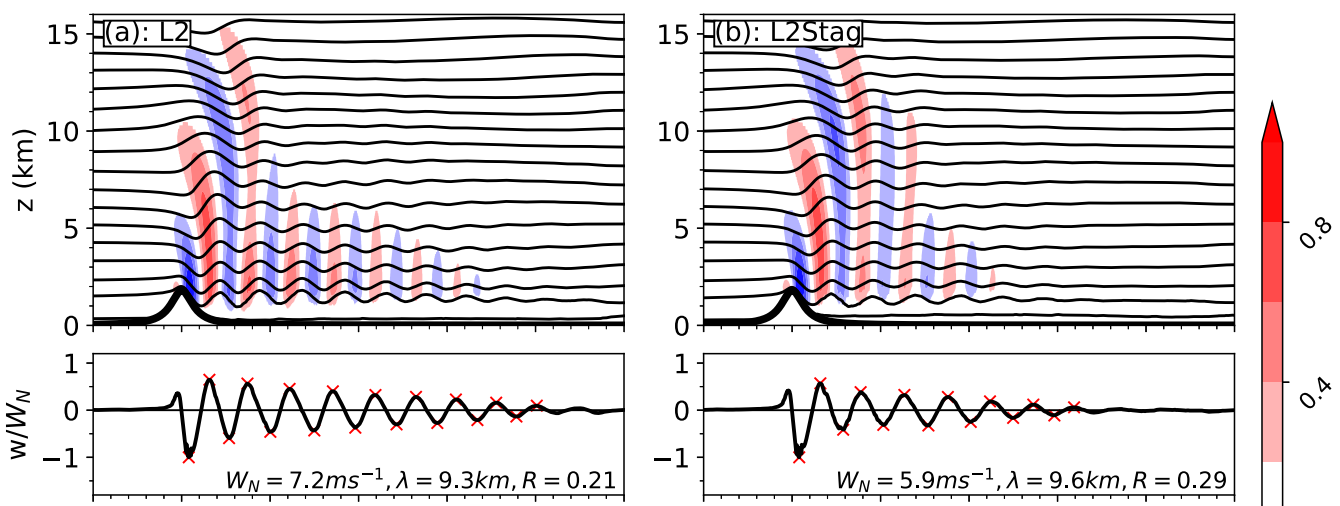

$0^{\alpha}$
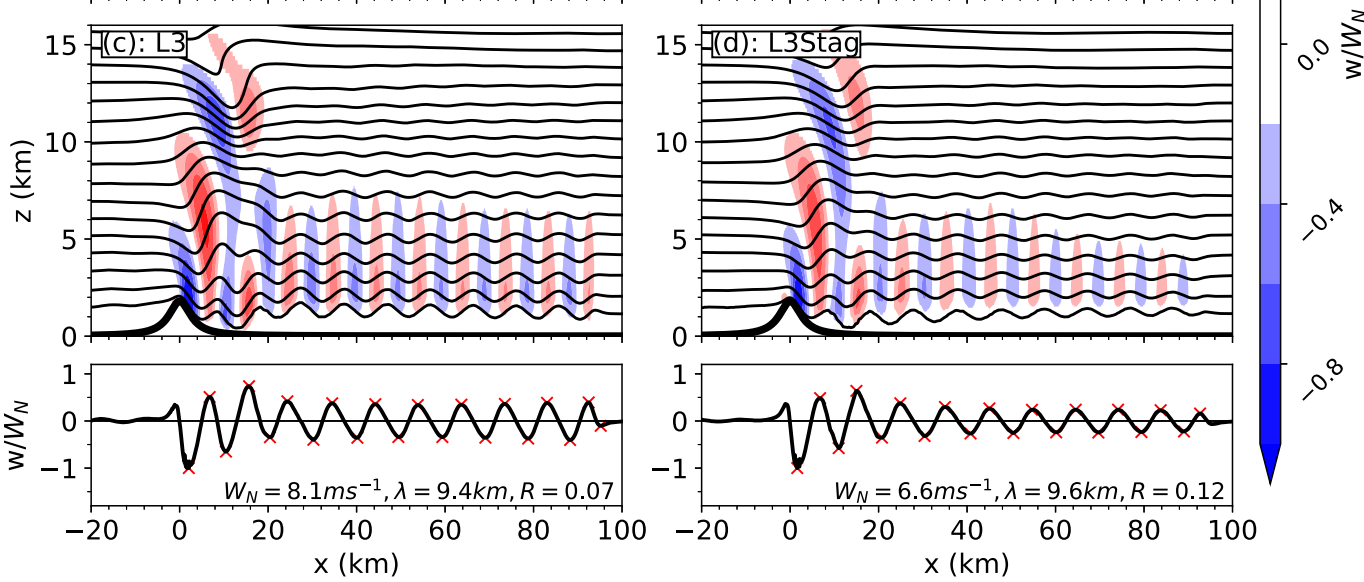

FIG. 7. As in Fig. 4, but for the simulations on the response to stagnant layer and ABL stability: (a) L2, (b) L2Stag, (c) L3, and (d) L3Stag.

increases, the Scorer parameter decreases and longer waves are reflected rather than propagating upward throughout the jet, and vice versa. More specifically, the comparison between L3 (Fig. 7c) and L3J40 (Fig. 8a) shows that the maximum amplitude $W_{N}$ is suppressed by the jet $\left(U_{\text {jet }}=40 \mathrm{~m} \mathrm{~s}^{-1}\right)$ although the mean wave amplitude $W$ seems to be increased (see Fig. $9 \mathrm{~b}$ and the potential temperature contours in Figs. 7c and $8 \mathrm{a})$. The most significant change occurs in $\lambda$ which increased by $25 \%$. To further investigate the wave response to the stronger jet $\left(U_{\text {jet }}=50 \mathrm{~m} \mathrm{~s}^{-1}\right)$ with the afternoon ABL, the case L3J50 shows that $\lambda$ is still the parameter that changed most significantly due to $U_{\text {jet }}$ (Fig. 8c), which is increased by more than $60 \%$ compared to $\lambda$ of case L3, while $W_{N}$ and $R$ stay relatively steady with the stronger $U_{\text {jet }}$. On the other hand, when the morning ABL is present, not only $\lambda$, but also both $W_{N}$ and $R$ are sensitive to $U_{\text {jet }}$ (Figs. $7 \mathrm{~b}$ and $8 \mathrm{~b}, \mathrm{c}$ ). Both the reduction of $W_{N}$ and the increase of $R$ indicate a stronger wave absorption with increasing $U_{\text {jet }}$ in the presence of the morning ABL. The above analysis shows that the wavelength increases with $U_{\text {jet }}$ no matter if a morning or an afternoon ABL is present, but the wave amplitude and damping ratio are more sensitive to the jet strength when a morning $\mathrm{ABL}$ is present.

To investigate the influence of the upper-level jet $\left(U_{\text {jet }}\right)$ on the waves for a wider range of values, four simulations are carried out with very weak jet $\left(U_{\text {jet }}=30 \mathrm{~m} \mathrm{~s}^{-1}\right)$ and very strong jet $\left(U_{\text {jet }}=60 \mathrm{~m} \mathrm{~s}^{-1}\right)$ for the morning and afternoon $\mathrm{ABL}$ conditions. It is shown that the maximum amplitude $W_{N}$ is largely reduced even when a weak jet $\left(U_{\text {jet }}=30 \mathrm{~m} \mathrm{~s}^{-1}\right)$ is present compared to the case without an upper-level jet, no matter whether the morning $\mathrm{ABL}$ or afternoon $\mathrm{ABL}$ is present (Fig. 9a). Further it is found that $W_{N}$ has only a small sensitivity to $U_{\text {jet }}$ for the afternoon $\mathrm{ABL}$ when the $U_{\text {jet }}$ is bigger than $20 \mathrm{~m} \mathrm{~s}^{-1}$ and smaller than $60 \mathrm{~m} \mathrm{~s}^{-1}$, but drops rapidly again when $U_{\text {jet }}$ is increased to $60 \mathrm{~m} \mathrm{~s}^{-1}$. $W_{N}$ is continually reducing with $U_{\text {jet }}$ for the morning ABL. However, the mean amplitude $W$ (averaged in the same distance as the mean wavelength $\lambda$ ) is slightly increasing with $U_{\text {jet }}$ and decreasing again when $U_{\text {jet }}=$ $60 \mathrm{~m} \mathrm{~s}^{-1}$, for both ABL conditions (Fig. 9b). It is clearly shown that both $W_{N}$ and $W$ are much smaller when the morning ABL is present (Figs. 9a,b). As stated previously, absorption may occur already at the first trough near the mountain, so that $R$ may underestimate the total absorption. A normalized wavedamping ratio, $R^{*}=R\left(W_{N}^{*}-W_{N}\right) / W_{N}$, is designed to account for the influence of $W_{N}$, where $W_{N}^{*}$ is $W_{N}$ of case L3. The plot of $R^{*}$ in Fig. 9c shows that the waves are decaying more rapidly with a stronger $U_{\text {jet }}$ when the morning $\mathrm{ABL}$ is present, while it stays steadier when the afternoon ABL is present except when $U_{\text {jet }}$ is very strong $\left(60 \mathrm{~m} \mathrm{~s}^{-1}\right)$. These results indicate that the wave damping is more sensitive to $U_{\text {jet }}$ when a morning $\mathrm{ABL}$ is presented. To explain this, the wavelength can be taken into account, which is shown to rapidly increase with $U_{\text {jet }}$ and not to be sensitive to the ABL condition. The simulations showed 

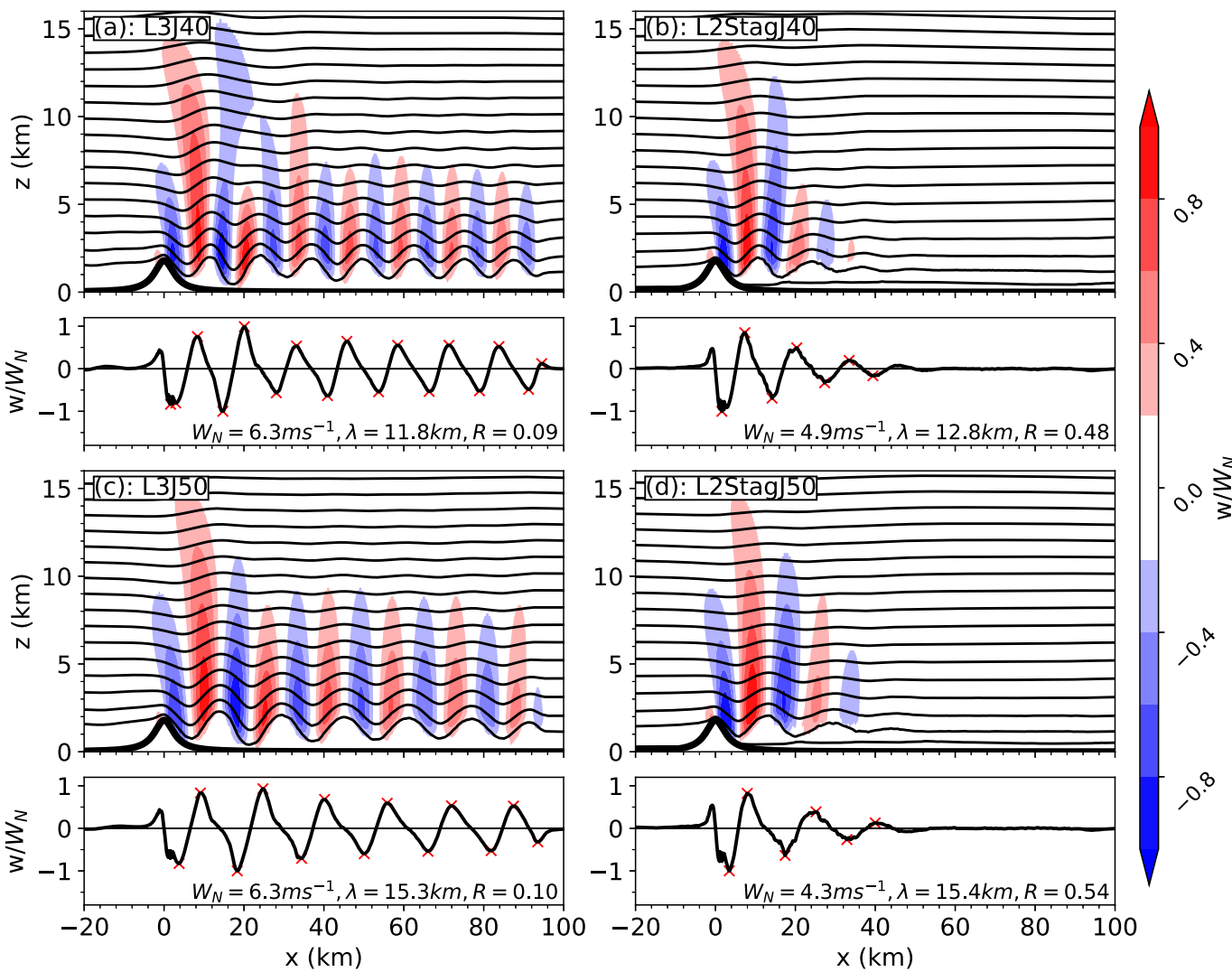

FIG. 8. As in Fig. 4, but for the simulations on the response to upper-level jet strength with morning or afternoon ABL condition: (a) L3J40, (b) L2StagJ40, (c) L3J50, and (d) L2StagJ50.

that the wave decays faster when the wavelength is longer (Jiang et al. 2006). Therefore, $R$ increases with $U_{\text {jet }}$ (or wavelength) when a stagnant and stable ABL are present in the morning, while it stays relatively steady with $U_{\text {jet }}$ when there is a neutral ABL without a stagnant layer in the afternoon.

\section{Momentum budget analysis}

Following Broad (2002), for a 2D $(x-z)$ inviscid, irrotational flow, to the leading order, the horizontal perturbation momentum equation can be written as

$$
\frac{\partial \rho_{0} u^{\prime}}{\partial t}=\frac{-\partial \rho_{0} u^{\prime} u^{\prime}}{\partial x}-\frac{\partial \rho_{0} u^{\prime} w^{\prime}}{\partial z}-\frac{\partial p^{\prime}}{\partial x}-\rho_{0} u_{0} \frac{\partial u^{\prime}}{\partial x}-\rho_{0} w^{\prime} \frac{\partial u_{0}}{\partial z}
$$

where $u^{\prime}, w^{\prime}$, and $p^{\prime}$ are the deviations of the zonal wind, vertical wind, and pressure from the horizontal mean zonal wind $u_{0}(z)$, vertical wind $w_{0}(z)=0$, and pressure $p_{0}(z)$, and $\rho_{0}(z)$ is the horizontal mean density. Considering a steady wave and neglecting the fifth term of rhs in (5), we now integrate (5) from $x_{m}$ to $x_{n}\left(x_{m}<x_{n}\right)$ :

$$
\begin{aligned}
0= & -\int_{x_{m}}^{x_{n}} \frac{\partial \rho_{0} u^{\prime} u^{\prime}}{\partial x} d x-\int_{x_{m}}^{x_{n}} \frac{\partial \rho_{0} u^{\prime} w^{\prime}}{\partial z} d x-\int_{x_{m}}^{x_{n}} \frac{\partial p^{\prime}}{\partial x} d x \\
& -\int_{x_{m}}^{x_{n}} \rho_{0} u_{0} \frac{\partial u^{\prime}}{\partial x} d x .
\end{aligned}
$$

If the waves are purely upward propagating, let $x_{m} \rightarrow-\infty$ and $x_{n} \rightarrow \infty$ so that $u^{\prime}, w^{\prime}$ and $p^{\prime}$ vanish at the boundaries. Therefore, the first, third, and fourth terms of rhs in (6) all vanish. Defining a horizontal averaging operator as $\left\langle M_{m, n}\right\rangle=\int_{x_{m}}^{x_{n}} M d x$ and letting $\tau_{w}=\rho_{0} u^{\prime} w^{\prime}$, we have

$$
0=\frac{-\partial\left\langle\tau_{w m, n}\right\rangle}{\partial z}
$$

Equation (7) expresses the Eliassen-Palm theorem (Eliassen and Palm 1960), in which the vertically transported horizontal momentum flux is constant with height as the wave propagates upward. As $u^{\prime}$ and $w^{\prime}$ are both zero at the surface because of the no-slip lower boundary condition, $\left\langle\tau_{w m, n}\right\rangle$ becomes zero at the surface. As $\left\langle\tau_{w m, n}\right\rangle$ is negative above the ABL, there must be an acceleration due to the reduced momentum flux in the ABL. In this layer, the pressure term [third rhs term in (6)], which can be reduced to $-\int_{-\infty}^{\infty} p_{s}^{\prime}(\partial h / \partial x) d x$, where $p_{s}^{\prime}$ is the surface pressure perturbation, will not be zero anymore because of the terrain undulation. Further, based on linear analysis (Phillips 1984), the upward propagating waves must break at heights where the air density is very small and the wave amplitude too large, which makes a momentum flux reduction at the breaking levels. Therefore, the wave-breaking layer is a momentum source, and the upward propagating gravity waves transport the momentum from the wave-breaking layer to the $\mathrm{ABL}$ as a 

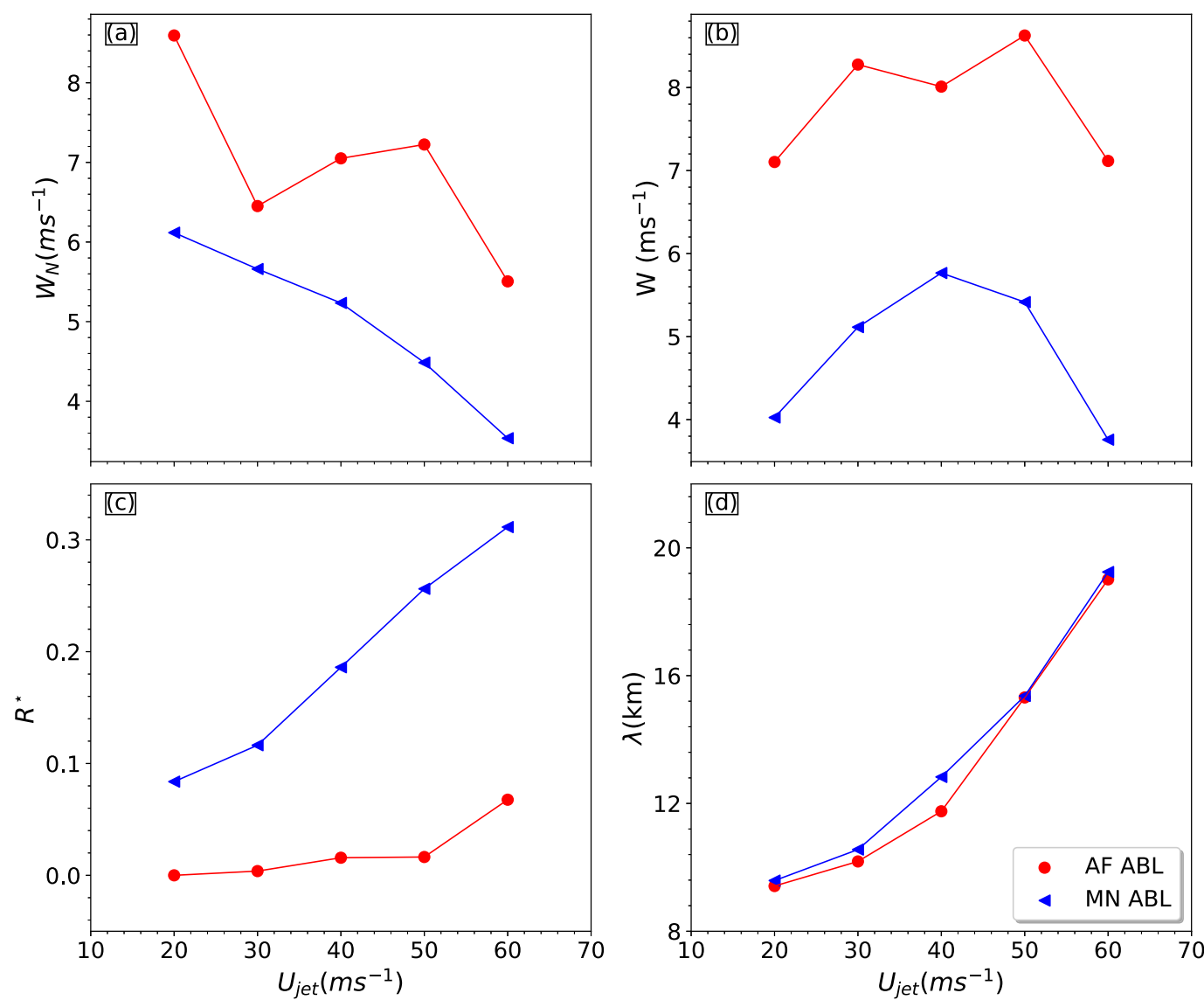

FIG. 9. (a) The maximum amplitude $\left(W_{N}\right)$, (b) mean amplitude $(W)$, (c) normalized wave-damping ratio $\left(R^{*}\right)$, and (d) mean wavelength $(\lambda)$ with different jet strength from $U_{\text {jet }}=20$ to $60 \mathrm{~m} \mathrm{~s}^{-1}$ for the morning ABL (blue) and afternoon ABL (red). Note that the jet strength of $20 \mathrm{~m} \mathrm{~s}^{-1}$ is the same as in the cases shown in Fig. 8 because the maximum zonal wind is $20 \mathrm{~m} \mathrm{~s}^{-1}$ and maintains constant over the lower-sheared layer in those cases.

momentum sink due to the pressure drag. In our simulations, a deep damping layer (denoted as DL) is imposed at the top of the domain which prohibits wave breaking, so that the momentum flux reduction practically occurs more gradually due to a damping scheme that is necessary for the numerical stability of the model integration instead of real wave braking.

If the waves are purely trapped, let $x_{m} \rightarrow-\infty$ and let $x_{n}=$ $x_{1}$, a downstream position where $w^{\prime}$ is maximum (one of the wave crests for $w$ ). Due to the Bernoulli functional, the perturbation pressure can be expressed as

$$
p=\frac{-\rho_{0}}{2}\left[u^{\prime 2}+2 u^{\prime} u_{0}+w^{\prime 2}+\left(N \eta^{\prime}\right)^{2}\right],
$$

where $\eta^{\prime}$ is the streamline displacement relative to its upstream undisturbed reference height (see, e.g., Broad 2002).

As $u^{\prime} \propto \cos (k x), w^{\prime} \propto \sin (k x)$, and $\eta^{\prime} \propto \cos (k x)$, where $k$ is the wavenumber, $u^{\prime}\left(x_{1}, z\right)=\eta^{\prime}\left(x_{1}, z\right)=0, w^{\prime}\left(x_{1}, z\right)=\hat{w}_{1}$ (wave crest at $\left.x_{1}\right)$, and $p\left(x_{1}, z\right)=-\rho_{0} w^{\prime}\left(x_{1}, z\right) / 2(\operatorname{Broad} 2002$; Jiang et al. 2006). Using the boundary condition at $x_{1}$ and substituting Eq. (8) into (6), we have

$$
0=\frac{-\partial\left\langle\tau_{w 0,1}\right\rangle}{\partial z}+\frac{\rho_{0}}{2} w^{\prime 2}\left(x_{1}, z\right)
$$

As the pressure drag term [the second term of rhs in (9)] is positive or zero, if the wave is totally damped at $x_{1}$, the averaged momentum flux is constant as in the propagating waves. However, unlike the propagating waves, the trapped waves are reflected by the upper layer so that the momentum flux is zero at any height. Otherwise if the trapped waves are not fully damped, the vertical momentum flux term must be negative because $w^{\prime} \neq 0$. Therefore, a positive pressure force is exerted to accelerate the flow, and the trapped wave tends to decelerate the flow in the trapped-wave layer (defined as the layer between the ABL and the reflection layer, and denoted as TWL). As the momentum flux at the reflection layer is zero, $\left\langle\tau_{w 0,1}\right\rangle$ must be negative and increase with height in the TWL. Because $\left\langle\tau_{w 0,1}\right\rangle$ is zero at the surface and negative in the TWL, $-\partial\left\langle\tau_{w 0,1}\right\rangle / \partial z$ must be positive in the ABL and a pressure drag is produced due to the undulation of the terrain.

As the trapped waves may horizontally propagate to further downstream, let $x_{m}=x_{1}$ and $x_{n}=x_{2}\left(x_{1}<x_{2}\right)$, where $x_{2}$ is another position where $u^{\prime}\left(x_{2}, z\right)=\eta^{\prime}\left(x_{2}, z\right)=0, w^{\prime}\left(x_{2}, z\right)=\hat{w}_{2}$ 

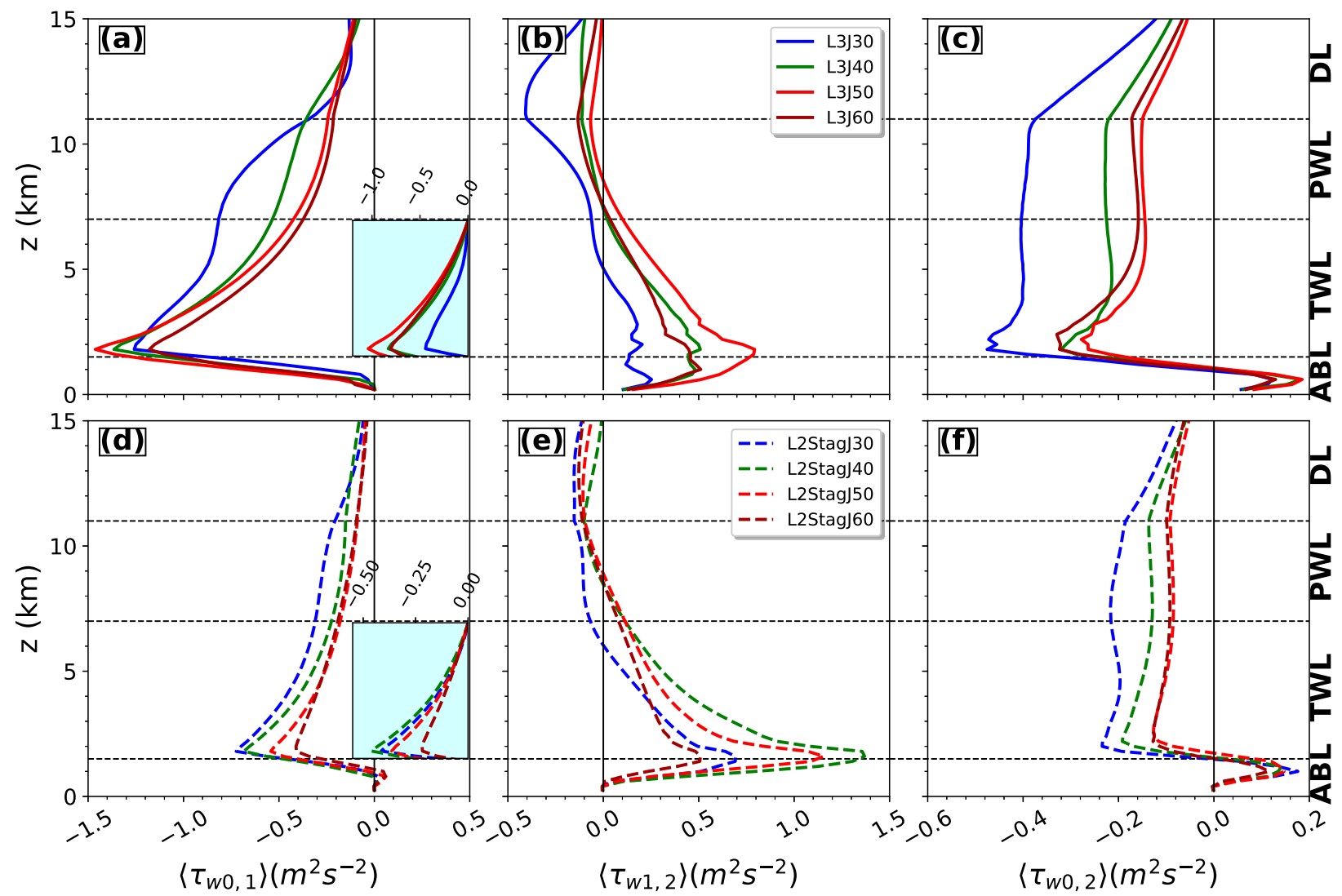

FIG. 10. Vertically transported horizontal wind momentum $\left(\tau_{w}\right) \cdot\left\langle\tau_{w m, n}\right\rangle$ refers to the normalized momentum flux integrated from $x_{m}$ to $x_{n}$. The integration boundaries are $x_{0}=-60 \mathrm{~km}$, and $x_{1}$ and $x_{2}$, which are the positions of the first and last diagnosed peak of $w$ for each case, respectively. The depths of the indicated layers are as follows: ABL, $0-1.5 \mathrm{~km}$ ( $=d_{s}$ in Table 2); TWL (trapped wave layer), 1.5-7 km; PWL (upward-propagating wave layer), 7-11 km; and DL (damping layer), $11 \mathrm{~km}$-model top. The nested plots in (a) and (d) show the deviation of the momentum flux profiles from their value at the top of the TWL at $7 \mathrm{~km}$.

(wave crest at $\left.x_{2}\right)$ and $p^{\prime}\left(x_{2}, z\right)=-\rho_{0} w^{\prime}\left(x_{2}, z\right) / 2$. Using the boundary condition at $x_{1}$ and $x_{2}$ and substituting Eq. (9) into (6) again, we have

$$
\frac{-\partial\left\langle\tau_{w 1,2}\right\rangle}{\partial z}=-\left[\frac{\rho_{0}}{2} w^{\prime 2}\left(x_{2}, z\right)-\frac{\rho_{0}}{2} w^{\prime 2}\left(x_{1}, z\right)\right]
$$

In contrast to $-\partial\left\langle\tau_{w 0,1}\right\rangle / \partial z<0$ between $x_{0}$ and $x_{1},-\partial\left\langle\tau_{w 1,2}\right\rangle / \partial z>0$ if the waves are decaying with $x$, and the trapped lee waves tend to accelerate the mean flow in the TWL because $\left\langle\tau_{w 0,1}\right\rangle$ must be positive and decrease with height in this layer. While $\left\langle\tau_{w 1,2}\right\rangle$ is zero at the surface and positive above the ABL, $-\partial\left\langle\tau_{w 1,2}\right\rangle / \partial z$ must be negative in the ABL. Therefore, downstream of the mountain the trapped lee waves transport horizontal momentum from the ABL to the TWL.

In summary, there are two momentum sources over the mountain between $x_{0}$ and $x_{1}$. The first one is the TWL just above the mountain and the other is the wave-breaking layer far aloft (DL in our simulations). Between $x_{0}$ and $x_{1}$, the momentum sink is located in the ABL due to the pressure drag. Further downstream between $x_{1}$ to $x_{2}$, the momentum source is located in the ABL, and the momentum sink is in the TWL aloft the ABL. There was a similar analysis in Jiang et al. (2006), but they did not clearly present the momentum flux and its impact on the mean flow in the ABL.

Figure 10 shows the momentum flux profiles averaged between $x_{0}(=-60 \mathrm{~km})$ and $x_{1}$ (the position of the first wave crest for $w$ ), between $x_{1}$ and $x_{2}$ (the position of the last wave crest for $w$ ), and between $x_{0}$ and $x_{2}$. Between $x_{0}$ and $x_{1}$, the averaged momentum flux is negative with its peak just above the ABL (Figs. 10a,d) as predicted by the theoretical analysis. While from $x_{1}$ to $x_{2}$, the averaged momentum flux is positive in the TWL with its peak just above the ABL (Figs. 10b,e). The negative momentum flux in the propagating wave layer (denoted as PWL) is associated with a part of upward propagating waves. From $x_{0}$ to $x_{2}$, as predicted by the theory, the averaged momentum flux is nearly constant in the PWL, which indicates most of the upward propagating waves are included between $x_{0}$ and $x_{2}$. The weaker jet can basically allow more waves propagating through the jet and produce more momentum flux in the PWL. However, if the jet is very strong (L3J60 and L2StagJ60), the averaged propagating-wave momentum flux is not reducing further (Figs. 10c,f). From $x_{0}$ to $x_{1}$, where both, propagating waves and trapped waves, contribute to the 

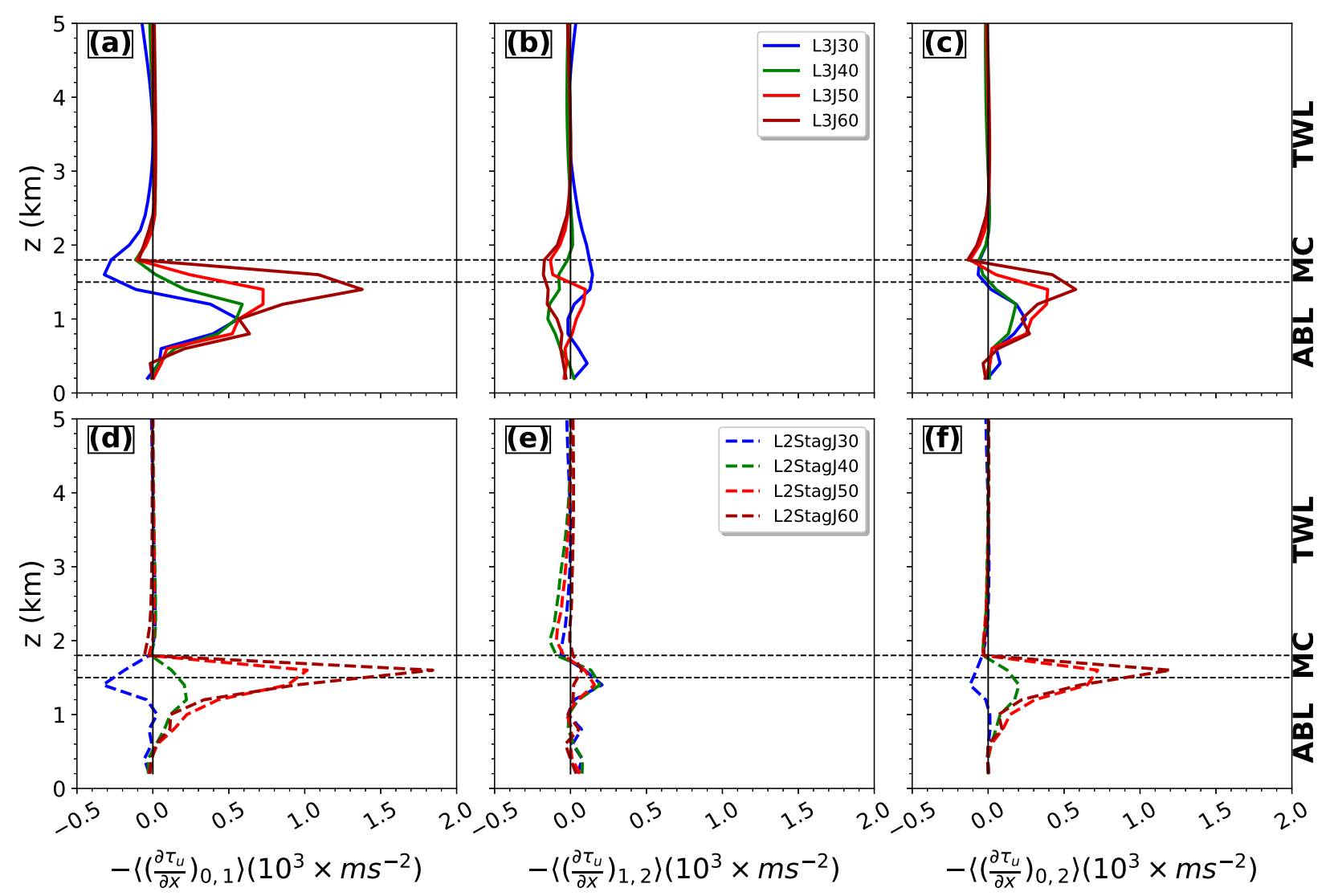

FIG. 11. Zonal-mean zonal convergence in the intervals (a),(d) $x_{0}-x_{1}$, (b),(e) $x_{1}-x_{2}$, and (c),(f) $x_{0}-x_{2}$ of the zonally transported zonal wind momentum term in which $\tau_{u}=\rho_{0} u^{\prime} u^{\prime}$. MC denotes the mountain crest level.

averaged momentum flux, the momentum flux difference between TWL and PWL (the slope of the lines in nested plots in Figs. 10a and 10d) can represent the averaged momentum flux induced by trapped waves over the mountain. Without the stable and stagnant and ABL, the stronger jet can produce a larger trapped-wave momentum flux except for L3J60 (Fig. 10a), which indicates that the stronger jet can induce stronger trapped waves. With the stable and stagnant ABL, the stronger jet can produce less trapped-wave momentum flux (Fig. 10a), which indicates the stable and stagnant layer is more efficient to absorb longer trapped waves.

When it comes to L3J60, the mean wave-damping ratio $R$ can be 0.19 (not shown) without a stable and stagnant ABL though, which indicates the waves can be absorbed if the waves are sufficiently long even if the ABL is neutral. This may explain why the momentum flux of L3J60 is smaller than that of L3J50 in Figs. 10a and 10b. The averaged trapped-wave momentum flux between $x_{0}$ and $x_{1}$ represents the momentum that is gained by the ABL, while the averaged momentum flux between $x_{1}$ and $x_{2}$ represents the momentum that is lost by the ABL. Comparing the nested plot in Fig. 10a (Fig. 10d) with Fig. 10b (Fig. 10f), we found it is clear that the more momentum the ABL gets over the mountain, the more the ABL loses in the downstream trapped region. Overall, the upper-level jet has multiple effects on the mountain waves. Basically, the jet strength can redistribute the ratio of upward propagating waves and trapped lee waves, i.e., the stronger jet can produce more trapped-wave and less propagating-wave momentum flux. However, the upward propagating-wave momentum flux may not continue to reduce when the jet exceeds a certain strength. When the ABL absorption becomes significant, the downward trapped-wave momentum flux over the mountain and the upward trapped-wave momentum flux in the downstream trapped-wave region are reducing with the jet strength as it is more efficient to absorb the longer waves associated with the stronger jet.

In Eq. (6), the horizontally transported momentum flux (denoted as $\tau_{u}$ ) term (the first term on the rhs) and the mean advection term (the fourth term on the rhs) can vanish if specific integral limits are selected. However, this may not be true in the layer below the mountain crest, because $u^{\prime}$ is not continuous at the place where the mountain is located. Figure 11 shows the horizontally transported momentum flux term averaged between $x_{0}$ and $x_{1}$, between $x_{1}$ and $x_{2}$, and between $x_{0}$ and $x_{2}$. This term is almost zero above the mountain crest level as predicted by the theoretical analysis but can be very large below the mountain crest (not shown but comparable to or even larger than the vertically transported horizontal momentum flux term). Comparison between Fig. 11a (Fig. 11d) with Fig. 11b (Fig. 11e) shows that this term mainly works 
between $x_{0}$ and $x_{1}$. This is reasonable because the nonlinear acceleration of the waves over the lee side can produce a severe downslope wind and as a consequence a horizontal wind gradient between the downslope region of the mountain and the regions further downstream. Figures $11 \mathrm{a}$ and $11 \mathrm{~d}$ show that the magnitude of this term is proportional to the jet strength, which means the trapped waves rather than the propagating waves can produce a larger horizontal wind gradient at the lee side. This may be because the stronger jet can produce stronger lee waves therefore a stronger wind gradient at the boundary separation between the downslope wind and rotor reverse flow. The mean advection term is not measured but should have a similar performance.

\section{Conclusions}

Diurnally evolving trapped lee waves have been observed frequently (Holmboe and Klieforth 1957; Queney et al. 1960), while the explanations of the phenomenon vary (Gerbier and Berenger 1961; Georgelin et al. 1996; Ralph et al. 1997; Jiang and Doyle 2008). Recently, a frequently observed gale phenomenon on the lee side of a mountain located on the southeastern Tibetan Plateau was simulated by the nested WRF Model with a $100-\mathrm{m}$ resolution and multiple-source observations (X20). As the westerly upper-level jet enhanced and the ABL developed in the afternoon, the trapped lee waves are amplified and lengthened. Such diurnally evolving lee waves may be significant in large areas of the southern Tibetan Plateau because of the many north-south ridges and because the westerly upper-level jet is steadily located in this region in wintertime (Schiemann et al. 2009). An idealized profile based on the realistic profile from the X20 study is designed to account for the low-level stagnant layer, the ABL stability and the upper-level jet. The ICON model is employed to investigate the mechanism behind diurnally evolving trapped lee waves with a large-eddy resolving configuration for mountain flow (ICON-MTN). The benchmarking simulations show that ICON-MTN can well reproduce the wave response due to the inversion layer above the ABL for different heights and different strengths (V04). The lateral boundary damping technique can satisfyingly deal with the inflows and outflows of the periodic domain, and the ABL turbulence can be well developed after a fetch distance of a few tens of kilometers.

The nonlinear effect from the increased mountain height has been investigated first, which shows that the wave amplitude is dramatically increased and the mean wavelength $(\lambda)$ is slightly increased with increased mountain height. The mean wavedamping ratio $(R)$ is reduced with increased mountain height, which may be a result from the nonlinear acceleration in the lee of the mountain that reduces the low-level wind stability. The filtered Richardson number $\left(\mathrm{Ri}_{f}\right)$ shows that the mean flow is indeed modified by the lee waves. Therefore, the nonlinearity from the increased mountain height plays a role in strongly amplifying and slightly lengthening the lee waves and promoting the lee-wave propagation.

The effect of the ABL stability and low-level stagnant layer on the lee waves has been investigated without a jet. The results show that either the low-level stagnant layer or the stable
ABL play a role as a wave-absorbing layer preventing the development of the trapped wave. The two factors can be superpositioned to reduce the maximum amplitude $\left(W_{N}\right)$ and increase the mean wave-damping ratio. The wavelength is not apparently sensitive to the ABL stability and the low-level stagnant layer (when depth is much smaller than the mountain height).

The wave response to the upper-level jet strength $\left(U_{\text {jet }}\right)$ has been investigated for the morning ABL (stable stability with a stagnant layer) and afternoon ABL (neutral stability without a stagnant layer). The maximum wave amplitude basically decreases with increasing $U_{\text {jet }}$. This may be interpreted as the weaker jet can produce more upward propagating waves that can extract more momentum from the upper layer to the downslope. However, the mean amplitude $(W)$, which mainly represents the amplitude of the trapped lee waves, is not strongly dependent on $U_{\text {jet }}$ when it is not very strong (e.g., $\left.60 \mathrm{~m} \mathrm{~s}^{-1}\right) . W$ is reduced largely when $U_{\text {jet }}$ is very strong, which may be interpreted as that the trapped lee waves are very long so that the wave absorption is significantly increased whenever the ABL is neutral or stable and stagnant. The mean wavelength increases with increased $U_{\text {jet }}$, which can further influence the wave absorption due to the morning ABL condition. The longer lee waves resulting from the stronger jet are more easily absorbed by the stable ABL and stagnant layer near the surface. Therefore, the wave response to the ABL condition is more sensitive when a jet is presented above.

The momentum budget has been diagnosed to show the wave-flow interaction due to the $\mathrm{ABL}$ structure and jet strength. The upward-propagating wave can transport momentum from higher layer where they are breaking, while the trapped waves can transport momentum from relatively lower levels where they are trapped. The momentum from the two wave components accelerates the ABL mean flow over the mountain region, while the momentum in the downstream region accelerates the mean flow in the trapped-wave layer (TWL) above the ABL. The jet strength can redistribute the amount of momentum due to upward-propagating waves and trapped lee waves. The stronger jet may induce smaller momentum fluxes due to upward-propagating waves but larger momentum fluxes due to trapped lee waves. However, both components are influenced largely by the ABL stability and stagnancy. When a morning $\mathrm{ABL}$ is present, both components are reduced, of which the trapped-wave momentum flux is further reduced with increased $U_{\text {jet }}$ because the longer waves are more easily absorbed by the ABL.

Finally, the mechanism of the diurnal evolution of waves over steep mountain under an upper-level jet can be summarized as 1) the developed ABL (both wind and stability) in the afternoon can remove the absorption layer, amplify the waves, and facilitate the horizontal wave propagation, 2) the stabilized ABL with a stagnant surface layer in the night and morning are more efficiently absorbing the longer lee waves due to the stronger upper-level jet. This phenomenon may be significant in other mountainous regions under a jet and have a large impact on the local-scale and large-scale circulation, which should be investigated in the future. It may be necessary to 
point out that this study focuses on the wave response on a steep small-scale mountain (half width $\sim 3 \mathrm{~km}$ ). When the mountain is big (e.g., half width $\sim 10 \mathrm{~km}$ ), the large-amplitude wave breaking and severe downslope windstorm similar to the chinook in the Rocky Mountains may occur (Scinocca and Peltier 1989). When mountains are too low to produce a stagnant layer in the valleys but still small (e.g., half width $\leq 3 \mathrm{~km}$ ), the conclusion resulted from this study may be still valid, because the ABL stratification alone can play a wave-absorbing/reflecting role evolving diurnally. However, this should be investigated carefully in the future. Last, the wave reflection/absorption is largely related to the filtered Richardson number $\left(\mathrm{Ri}_{f}\right)$, which represents the local flow stability. The $\mathrm{Ri}_{f}$ itself is related to the lee waves in turn, due to the large-scale background atmospheric condition or the mountain height. Therefore, the wave and its horizontally propagation are interactive; e.g., a higher mountain can produce stronger downslope winds which can produce a larger area of low- $\mathrm{Ri}_{f}$ layer that can facilitate the wave propagation. This phenomenon is also observed for other cases in our study and should be investigated further in the future.

Acknowledgments. The research was conducted with financial support from the National Natural Science Foundation of China (under Grants 41875123 and 91637210) and with support of the Max Planck Institute for Meteorology (MPI-M) and Chinese Scholarship Council during a visit of Haile Xue at MPI-M. We thank Bjorn Stevens and Claudia Stephan from MPI-M for their prereview and comments and James Doyle from the Naval Research Laboratory for his kind help in model configuration. Computations were carried out at the German Climate Computing Center/Deutsches Klimarechenzentrum (DKRZ) on the "Mistral" super computer. The ICON code is available under the ICON Software License Agreement (ISLA) version 2.1 of the German Weather Service DWD and the MPI-M (https://www.mpimet.mpg.de/en/science/models/license).

\section{REFERENCES}

Baldauf, M., and S. Brdar, 2016: 3D diffusion in terrain-following coordinates: Testing and stability of horizontally explicit, vertically implicit discretizations. Quart. J. Roy. Meteor. Soc., 142, 2087-2101, https://doi.org/10.1002/qj.2805.

Broad, A. S., 2002: Momentum flux due to trapped lee waves forced by mountains. Quart. J. Roy. Meteor. Soc., 128, 2167-2173, https://doi.org/10.1256/003590002320603593.

Clark, T. L., and W. R. Peltier, 1977: On the evolution and stability of finite amplitude mountain waves. J. Atmos. Sci., 34, 1715-1730, https://doi.org/10.1175/1520-0469(1977)034<1715: OTEASO $>2.0 . \mathrm{CO} ; 2$.

— culations in two and three spatial dimensions using anelastic interactive grid nesting: A possible mechanism for gustiness. J. Atmos. Sci., 41, 329-350, https://doi.org/10.1175/15200469(1984)041<0329:SDWCIT>2.0.CO;2.

Corby, G. A., and C. E. Wallington, 1956: Airflow over mountains: The lee-wave amplitude. Quart. J. Roy. Meteor. Soc., 82, 266274, https://doi.org/10.1002/qj.49708235303.

Dipankar, A., B. Stevens, R. Heinze, C. Moseley, G. Zängl, M. Giorgetta, and S. Brdar, 2015: Large eddy simulation using the general circulation model ICON. J. Adv. Model. Earth Syst., 7, 963-986, https://doi.org/10.1002/2015MS000431.

Doyle, J. D., and D. R. Durran, 2002: The dynamics of mountainwave-induced rotors. J. Atmos. Sci., 59, 186-201, https://doi.org/ 10.1175/1520-0469(2002)059<0186:TDOMWI >2.0.CO;2.

$\longrightarrow$, and - 2007: Rotor and subrotor dynamics in the lee of three-dimensional terrain. J. Atmos. Sci., 64, 4202-4221, https://doi.org/10.1175/2007JAS2352.1.

Durran, D. R., 1986a: Another look at downslope windstorms. Part I: The development of analogs to supercritical flow in an infinitely deep, continuously stratified fluid. J. Atmos. Sci., 43, 2527-2543, https://doi.org/10.1175/1520-0469(1986)043<2527: ALADWP $>2.0 . \mathrm{CO} ; 2$.

_ 1986b: Mountain waves. Mesoscale Meteorology and Forecasting, P. S. Ray, Ed., Amer. Meteor. Soc., 472-492.

- 1990: Mountain waves and downslope winds. Atmospheric Processes over Complex Terrain, Meteor. Monogr., No. 45, Amer. Meteor. Soc., 59-81.

Eliassen, A., and E. Palm, 1960: On the transfer of energy in stationary mountain waves. Geophys. Publ., 22, 1-23.

Georgelin, M., E. Richard, and M. Petididier, 1996: The impact of diurnal cycle on a low-Froude number flow observed during the PYREX experiment. Mon. Wea. Rev., 124, 1119-1131, https://doi.org/10.1175/1520-0493(1996)124<1119: TIODCO $>2.0 . \mathrm{CO} ; 2$.

Gerbier, N., and M. Berenger, 1961: Experimental studies of lee waves in the French Alps. Quart. J. Roy. Meteor. Soc., 87, 1323, https://doi.org/10.1002/qj.49708737103.

Giorgetta, M. A., and Coauthors, 2018: ICON-A: The atmospheric component of the ICON Earth system model. Part I: Model description. J. Adv. Model. Earth Syst., 10, 1613-1637, https:// doi.org/10.1029/2017MS001242.

Heinze, R., and Coauthors, 2017: Large-eddy simulations over Germany using ICON: A comprehensive evaluation. Quart. J. Roy. Meteor. Soc., 143, 69-100, https://doi.org/10.1002/ qj.2947.

Holmboe, J., and H. Klieforth, 1957: Investigations of mountain lee waves and airflow over the Sierra Nevada. University of California, Los Angeles, Dept. of Meteorology Rep., 290 pp.

Inoue, M., G. Matheou, and J. Teixeira, 2014: LES of a spatially developing atmospheric boundary layer: Application of a fringe method for the stratocumulus to shallow cumulus cloud transition. Mon. Wea. Rev., 142, 3418-3424, https://doi.org/ 10.1175/MWR-D-13-00400.1.

Jiang, Q., and J. D. Doyle, 2008: On the diurnal variation of mountain waves. J. Atmos. Sci., 65, 1360-1377, https://doi.org/ 10.1175/2007JAS2460.1.

,-- , and R. B. Smith, 2006: Interaction between trapped waves and boundary layers. J. Atmos. Sci., 63, 617-633, https:// doi.org/10.1175/JAS3640.1.

Klemp, J. B., and D. R. Lilly, 1975: The dynamics of wave-induced downslope winds. J. Atmos. Sci., 32, 320-339, https://doi.org/ 10.1175/1520-0469(1975)032<0320:TDOWID >2.0.CO;2.

_ J. Judhia, and A. D. Hassiotis, 2008: An upper gravity-wave absorbing layer for NWP applications. Mon. Wea. Rev., 136, 3987-4004, https://doi.org/10.1175/2008MWR2596.1.

Klocke, D., M. Brueck, C. Hohenegger, and B. Stevens, 2017: Rediscovery of the doldrums in storm-resolving simulations over the tropical Atlantic. Nat. Geosci., 10, 891-896, https:// doi.org/10.1038/s41561-017-0005-4.

Lilly, D. K., 1962: On the numerical simulation of buoyant convection. Tellus, 14, 148-172, https://doi.org/10.3402/ tellusa.v14i2.9537. 
Lorenz, E. N., 1960: Energy and numerical weather prediction. Tellus, 12, 364-373, https://doi.org/10.3402/tellusa.v12i4.9420.

Lott, F., 2007: The reflection of a stationary gravity wave by a viscous boundary layer. J. Atmos. Sci., 64, 3363-3371, https:// doi.org/10.1175/JAS4020.1.

— 2016: A new theory for downslope windstorms and trapped mountain waves. J. Atmos. Sci., 73, 3585-3597, https://doi.org/ 10.1175/JAS-D-15-0342.1.

Munters, W., C. Meneveau, and J. Meyers, 2016: Turbulent inflow precursor method with time-varying direction for large-eddy simulations and applications to wind farms. Bound.-Layer Meteor., 159, 305-328, https://doi.org/10.1007/s10546-016-0127-z.

Narcowich, F. J., and J. D. Ward, 1994: Generalized Hermite interpolation via matrix-valued conditionally positive definite functions. Math. Comput., 63, 661-687, https://doi.org/10.1090/ S0025-5718-1994-1254147-6.

Ólafsson, H., and P. Bougeault, 1997: The effect of rotation and surface friction on orographic drag. J. Atmos. Sci., 54, 193-210, https://doi.org/10.1175/1520-0469(1997)054<0193:TEORAS > 2.0.CO;2.

Pearce, R. P., and P. W. White, 1967: Lee wave characteristics derived from a three-layer model. Quart. J. Roy. Meteor. Soc., 93, 155-165, https://doi.org/10.1002/qj.49709339602.

Peltier, W. R., and J. F. Scinocca, 1990: The origin of severe downslope windstorm pulsations. J. Atmos. Sci., 47, 2853-2870, https://doi.org/10.1175/1520-0469(1990)047<2853: TOOSDW $>2.0 . \mathrm{CO} ; 2$.

Phillips, D. S., 1984: Analytical surface pressure and drag for linear hydrostatic flow over three-dimensional elliptical mountains. J. Atmos. Sci., 41, 1073-1084, https://doi.org/10.1175/15200469(1984)041<1073:ASPADF>2.0.CO;2.

Queney, P., G. A. Corby, N. Gerbier, H. Koschmieder, and J. Zierep, 1960: The airflow over mountains. WMO Tech. Note 34, 135 pp.

Ralph, F. M., P. J. Neiman, T. L . Keller, D. Levinson, and L. Fedor, 1997: Observations, simulations and analysis of nonstationary trapped lee waves. J. Atmos. Sci., 54, 1308-1333, https://doi.org/10.1175/1520-0469(1997)054<1308:OSAAON> 2.0.CO;2.

Reinecke, P. A., and D. R. Durran, 2008: Estimating topographic blocking using a Froude number when the static stability is nonuniform. J. Atmos. Sci., 65, 1035-1048, https://doi.org/ 10.1175/2007JAS2100.1.

Sachsperger, J., S. Serafin, and V. Grubišić, 2015: Lee waves on the boundary-layer inversion and their dependence on freeatmospheric stability. Front. Earth Sci., 3, 70, https://doi.org/ 10.3389/feart.2015.00070.

_, I. Stiperski, and A. Paci, 2017: The amplitude of lee waves on the boundary-layer inversion. Quart. J. Roy. Meteor. Soc., 143, 27-36, https://doi.org/10.1002/qj.2915.

Sauer, J. A., D. Muñoz-Esparza, J. M. Canfield, K. R. Costigan, R. R. Linn, and Y. Kim, 2016: A large-eddy simulation study of atmospheric boundary layer influence on stratified flows over terrain. J. Atmos. Sci., 73, 2615-2632, https://doi.org/ 10.1175/JAS-D-15-0282.1.

Sawyer, J. S., 1960: Numerical calculation of the displacements of a stratified airstream crossing a ridge of small height. Quart. J. Roy. Meteor. Soc., 86, 326-345, https://doi.org/10.1002/ qj. 49708636905.

Schiemann, R., D. Lüthi, and C. Schär, 2009: Seasonality and interannual variability of the westerly jet in the Tibetan Plateau region. J. Climate, 22, 2940-2957, https://doi.org/10.1175/ 2008JCLI2625.1.

Scinocca, J., and W. Peltier, 1989: Pulsating downslope windstorms. J. Atmos. Sci., 46, 2885-2914, https://doi.org/10.1175/15200469(1989)046<2885:PDW>2.0.CO;2.

Scorer, R. S., 1949: Theory of waves in the lee of mountains. Quart. J. Roy. Meteor. Soc., 75, 41-56, https://doi.org/ 10.1002/qj.49707532308.

— , and H. Klieforth, 1959: Theory of mountain waves of large amplitude. Quart. J. Roy. Meteor. Soc., 85, 131-143, https:// doi.org/10.1002/qj.49708536406.

Smith, R. B., S. Skubis, J. D. Doyle, A. S. Broad, C. Kiemle, and H. Volkert, 2002: Mountain waves over Mont Blanc: Influence of a stagnant boundary layer. J. Atmos. Sci., 59, 2073-2092, https:// doi.org/10.1175/1520-0469(2002)059<2073:MWOMBI >2.0.CO;2.

— , Q. Jiang, and J. D. Doyle, 2006: A theory of gravity wave absorption by a boundary layer. J. Atmos. Sci., 63, 774-781, https://doi.org/10.1175/JAS3631.1.

Soufflet, C., F. Lott, and F. Damiens, 2019: Trapped mountain waves with a critical level just below the surface. Quart. J. Roy. Meteor. Soc., 145, 1503-1514, https://doi.org/10.1002/qj.3507.

Teixeira, M. A., J. L. Argaín, and P. M. Miranda, 2013: Orographic drag associated with lee waves trapped at an inversion. J. Atmos. Sci., 70, 2930-2947, https://doi.org/10.1175/JAS-D12-0350.1.

Vosper, S. B., 2004: Inversion effects on mountain lee waves. Quart. J. Roy. Meteor. Soc., 130, 1723-1748, https://doi.org/ 10.1256/qj.03.63.

Xue, H., J. Li, T. Qian, and H. Gu, 2020: A 100-m-scale modeling study of a gale event on the lee side of a long narrow mountain. J. Appl. Meteor. Climatol., 59, 23-45, https://doi.org/10.1175/ JAMC-D-19-0066.1.

Zang, Z.-L., and M. Zhang, 2008: A study of the environmental influence on the amplitude of lee waves. Adv. Atmos. Sci., 25, 474-480, https://doi.org/10.1007/s00376-008-0474-x.

,-- , and H. Huang, 2007: Influence of the Scorer parameter profile on the wavelength of trapped lee waves. J. Hydrodyn., 19, 165-172, https://doi.org/10.1016/S1001-6058(07)60044-4.

Zängl, G., D. Reinert, P. Ripodas, and M. Baldauf, 2015: The ICON (Icosahedral Non-Hydrostatic) modelling framework of DWD and MPI-M: Description of the non-hydrostatic dynamical core. Quart. J. Roy. Meteor. Soc., 141, 563-579, https:// doi.org/10.1002/qj.2378. 